\title{
Genome-wide target profiling of piggyBac and Tol2 in HEK 293: pros and cons for gene discovery and gene therapy
}

\author{
Yaa-Jyuhn J Meir ${ }^{1 *}$, Matthew T Weirauch ${ }^{2}$, Herng-Shing Yang ${ }^{3}$, Pei-Cheng Chung ${ }^{4}$, Robert K Yu ${ }^{5}$ and Sareina C-Y Wu ${ }^{4 *}$
}

\begin{abstract}
Background: DNA transposons have emerged as indispensible tools for manipulating vertebrate genomes with applications ranging from insertional mutagenesis and transgenesis to gene therapy. To fully explore the potential of two highly active DNA transposons, piggyBac and Tol2, as mammalian genetic tools, we have conducted a sideby-side comparison of the two transposon systems in the same setting to evaluate their advantages and disadvantages for use in gene therapy and gene discovery.

Results: We have observed that (1) the Tol2 transposase (but not piggyBac) is highly sensitive to molecular engineering; (2) the piggyBac donor with only the 40 bp 3'-and 67 bp 5'-terminal repeat domain is sufficient for effective transposition; and (3) a small amount of piggyBac transposases results in robust transposition suggesting the piggyBac transpospase is highly active. Performing genome-wide target profiling on data sets obtained by retrieving chromosomal targeting sequences from individual clones, we have identified several piggyBac and Tol2 hotspots and observed that (4) piggyBac and Tol2 display a clear difference in targeting preferences in the human genome. Finally, we have observed that (5) only sites with a particular sequence context can be targeted by either piggyBac or Tol2.

Conclusions: The non-overlapping targeting preference of piggyBac and Tol2 makes them complementary research tools for manipulating mammalian genomes. PiggyBac is the most promising transposon-based vector system for achieving site-specific targeting of therapeutic genes due to the flexibility of its transposase for being molecularly engineered. Insights from this study will provide a basis for engineering piggyBac transposases to achieve site-specific therapeutic gene targeting.
\end{abstract}

\section{Background}

DNA transposons are natural genetic elements residing in the genome as repetitive sequences. A simple transposon is organized by terminal repeat domains (TRDs) embracing a gene encoding a catalytic protein, transposase, required for its relocation in the genome through a "cut-and-paste" mechanism. Since the first discovery of DNA transposons in Maize by Barbara\#McClintock in 1950 [1], transposons have been used extensively as genetic tools in invertebrates and in plants for

\footnotetext{
* Correspondence: jmeir@mail.cgu.edu.tw; sareinaw@mail.cgu.edu.tw 'Department of Biomedical Sciences, Chang Gung University, 259 Wen-Hwa 1st Road, Kwei-Shan, Tao-Yuan 333, Taiwan

${ }^{4}$ Molecular Medicine Research Center, Chang Gung University, 259 Wen-Hwa 1st Road, Kwei-Shan, Tao-Yuan 333, Taiwan

Full list of author information is available at the end of the article
}

transgenesis and insertional mutagenesis [2-7]. Such tools, however, have not been available for genome manipulations in vertebrates or mammals until the reactivation of a Tc1/mariner-like element, Sleeping Beauty, from fossils in the salmonid fish genome [8]. Since its awakening, Sleeping Beauty has been used as a tool for versatile genetic applications ranging from transgenesis to functional genomics and gene therapy in vertebrates including fish, frogs, mice, rats and humans [9]. Subsequently, naturally existing transposons, such as Tol2 and piggyBac, have also been shown to effectively transpose in vertebrates.

The Medaka fish (Orizyas latipes) Tol2, belonging to the $h A T$ family of transposons, is the first known naturally occurring active DNA transposon discovered in vertebrate genomes [10]. Tol2 is a standard tool for

\section{Biomed Central}


manipulating zebrafish genomes and has been demonstrated to transpose effectively in frog, chicken, mouse and human cells as well [11]. Recent studies found that Tol2 is an effective tool both for transgenesis via pronuclear microinjection and germline insertional mutagenesis in mice [12]. Cabbage looper moth (Trichoplusia ni) piggyBac is the founder of the piggyBac superfamily and is widely used for mutagenesis and transgenesis in insects [13]. Recently, piggyBac was shown to be highly active in mouse and human cells and has emerged as a promising vector system for chromosomal integration, including insertional mutagenesis in mice and nuclear reprogramming of mouse fibroblasts to induced-pluripotent stem cells [14-19].

To date, most gene therapy trials have utilized viral vectors for permanent gene transfer due to their high transduction rate and their ability to integrate therapeutic genes into host genomes for stable expression. However, serious problems associated with most viral vectors, such as limited cargo capacity, host immune response, and oncogenic insertions (as evidenced by the retrovirus-based gene therapy) highlight an urgent need for developing effective non-viral therapeutic gene delivery systems [20,21]. Recently, Sleeping Beauty, Tol2, and piggyBac transposon-based vector systems have been explored for their potential use in gene therapy with proven successes [22-25]. However, for therapeutic purposes, a large cargo capacity is often required. The transposition efficiency of Sleeping Beauty is reduced in a size-dependent manner with $50 \%$ reduction in its activity when the size of the transposon reaches $6 \mathrm{~kb}$ [26]. Tol2 and piggyBac, however, are able to integrate up to 10 and $9.1 \mathrm{~kb}$ of foreign DNA into the host genome, respectively, without a significant reduction in their transposition activity [14,22]. Additionally, by a direct comparison, we have observed that Tol2 and piggyBac are highly active in all mammalian cell types tested, unlike SB11 (a hyperactive Sleeping Beauty), which exhibits a moderate and tissue-dependent activity [15]. Because of their high cargo capacity and high transposition activity in a broad range of vertebrate cell types, piggyBac and Tol2 are two promising tools for basic genetic studies and preclinical experimentation. Our goal here was to evaluate the pros and cons of piggyBac and Tol2 for the use in gene therapy and gene discovery by performing a side-by-side comparison of both transposon systems. In this study, we reported for the first time the identification of the shortest effective piggyBac TRDs as well as several piggyBac and Tol2 hotspots. We also observed that piggyBac and Tol2 display non-overlapping targeting preferences, which makes them complementary research tools for manipulating mammalian genomes. Furthermore, piggyBac appears to be the most promising vector system for achieving specific targeting of therapeutic genes due to a robust enzymatic activity of the piggyBac transposase and flexibility the transposase displays towards molecular engineering. Finally, results of our in-depth analyses of piggyBac target sequences highlight the need to first scrutinize the piggyBac favored target sites for the therapeutic cell type of interest before designing a customized DNA binding protein for fusing with the piggyBac transposase to achieve site-specific therapeutic gene targeting.

\section{Results}

Transposition activity of piggyBac and Tol2 in mammalian cells

With the ultimate goal of identifying and targeting safe sites in the genome at which to insert corrective genes, we previously explored three active mammalian transposases, piggyBac, Tol2 and SB11 (a hyperactive Sleeping Beauty) for their sensitivity to molecular modification [15]. After fusing the GAL4 DNA binding domain to the $\mathrm{N}$-terminus of the three transposases, we only detected a slight change in the activity of the piggyBac transposase, whereas the same modification nearly abolished the activity of Tol2 and SB11 [15]. A recent genetic screen has yielded a novel hyperactive Sleeping Beauty transposase (designated as SB100X) that was shown to be more active than piggyBac under restrictive conditions that support their peak activity [28]. However, in this study we chose to focus on piggyBac and Tol2 but not Sleeping Beauty for the following reasons: (1) all of the reported attempts to modify the $S B 11$ transposase either $\mathrm{N}$ - or $\mathrm{C}$-terminally result in a complete elimination or a significant reduction in transposase activity; (2) Sleeping Beauty is more susceptible to over expression inhibition than piggyBac and Tol2; (3) the cargo capacity of Sleeping Beauty is limited; and (4) unlike Tol2 and piggyBac that are active in all mammalian cell types tested, Sleeping Beauty display cell-type dependent activity $[15,27,34]$.

We have demonstrated that piggyBac and Tol2 display high transposition activity in several cell lines [15]. We now wish to explore the possibility of further enhancing their activity by trimming non-essential sequences from both transposons. Using a PCR-based strategy we generated $\mathrm{pPB}$-cassette3short with the shortest TRDs reported replacing the long ones of the pXLBacII-cassette (Figure 1A) [29,30]. Similarly, based on the previous report, a new Tol 2 donor, pTol2mini-cassette, with minimal terminal repeats [31] replacing the long ones of Tol2ends-cassette was also constructed (Figure 1A). The new helper plasmids of piggyBac (pPRIG-piggyBac) and Tol2 (pPRIG-Tol2) were also constructed by placing cDNA of piggyBac and Tol2 transposases, respectively, in the bi-cistronic transcriptional unit with 


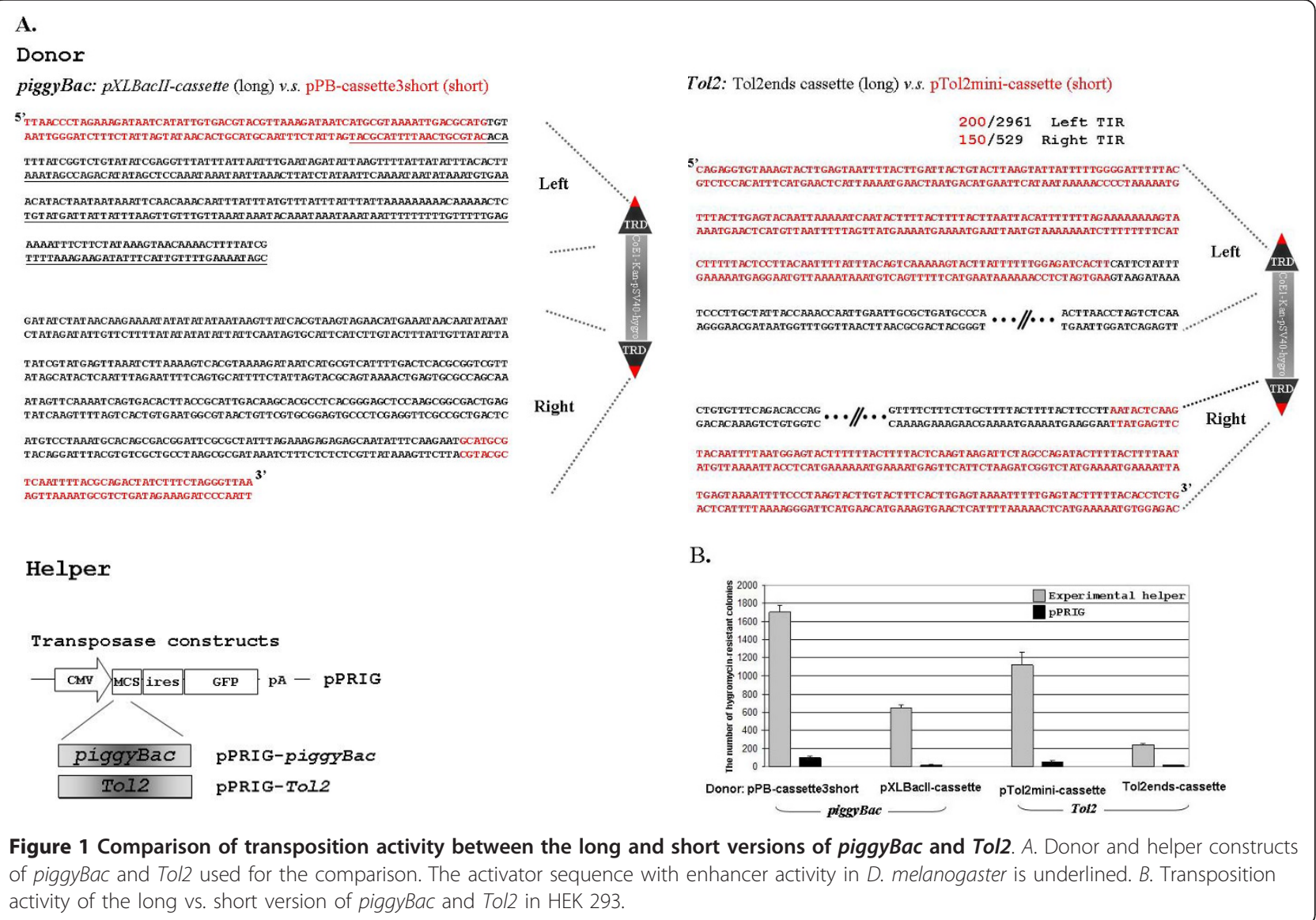

GFP driven by the CMV promoter in the pPRIG vector (a gift kindly provided by Dr. Patrick Martin) (Figure 1A). To compare the transposition activity of the long versus short version of piggyBac and Tol2, the piggyBac or Tol2 donor with either long or short TRDs was cotransfected with its helper plasmid into HEK 293 cells. The transfected cells were subjected to a chromosomal transposition assay (as detailed in reference 32) to determine their transposition activity. Removing the majority of the terminal repeat sequences of piggyBac and Tol2 resulted in a 2.6- and 4.7-fold increase in transposition activity as compared to their wild-type counterparts (Figure 1B). Given that the sizes of the piggyBac and Tol2 donor plasmids are reduced by 1.75 -and 1.4- fold, respectively, the observed increases in transposition activity for piggyBac and Tol2 are in effect 1.5- and 3.3fold when normalized by the number of donor molecules transfected. True transpositions of pPB-cassette3short and pTol2mini-cassette in HEK 293 were further confirmed by retrieving chromosomal sequences flanking their target site (data not shown).

In order to further explore their potential to be modified by molecular engineering, we Myc tagged the $\mathrm{N}$-terminus of the piggyBac transposase (Myc-piggyBac) and
HA tagged both the $\mathrm{N}$ - or C-terminus of the Tol2 transposase (HA-Tol2 and Tol2-HA) (Figure 2A). By cotransfecting pPB-cassette3short, and the helper plasmid expressing either wild-type or the chimeric piggyBac transposase into HEK 293 cells, we observed a slight increase in activity with the Myc-piggyBac as compared to its wild type counterpart (Figure 2B). An increase in activity after molecular modifications was also observed in several of our piggyBac chimeras including the GAL4-piggyBac which displayed a fluctuated activity that was sometimes higher than the wild-type piggyBac transposase (15 and Meir et. al., unpublished observations). Similar approaches, however, demonstrated that fusing the HA tag to either end of the Tol2 transposase almost completely eliminated its activity (Figure 2B).

To evaluate the activity of the piggyBac transposase, we then transfected a fixed amount of piggyBac donors (100 ng) with a various amount of helper plasmids bearing Myc-tagged piggyBac transposases (ranging from 50 to $300 \mathrm{ng}$ ) into HEK 293. PiggyBac transposition activity increases as the amount of piggyBac transposases increase until reaching its peak in cells transfected with $200 \mathrm{ng}$ of helper plasmids (Figure 2C). As the amount of piggyBac transposases were reduced to the level 
A.

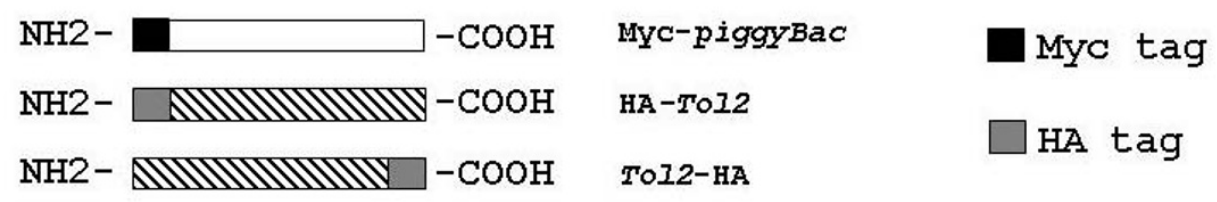

B.
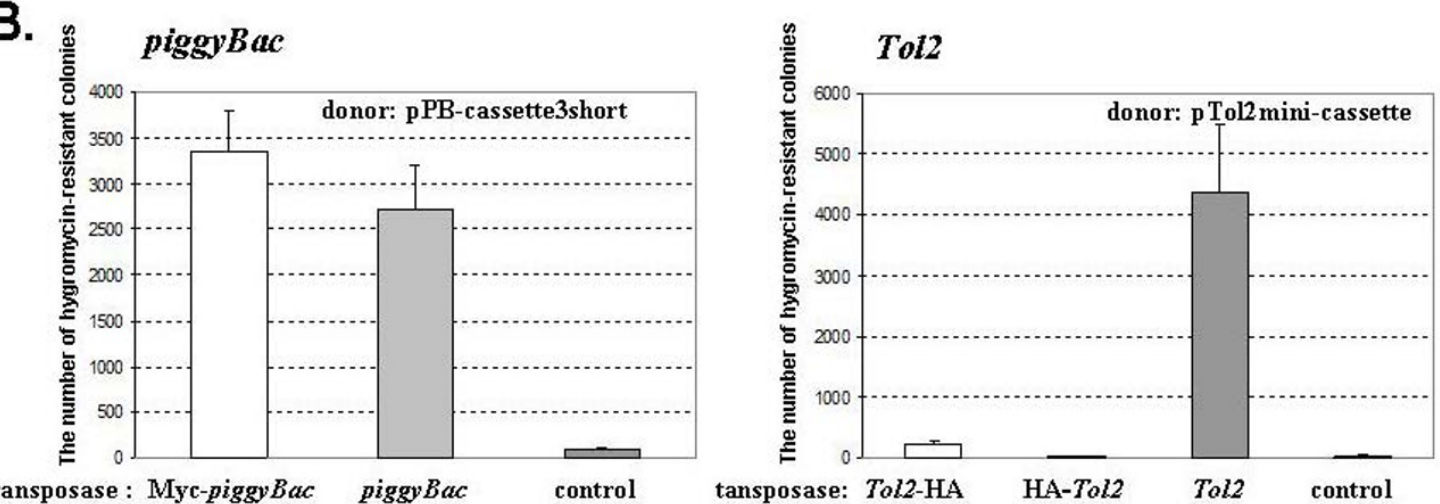

transposase : Myc-piggyBac piggyBac

control

tansposase: Tol2-HA

Tols

C.
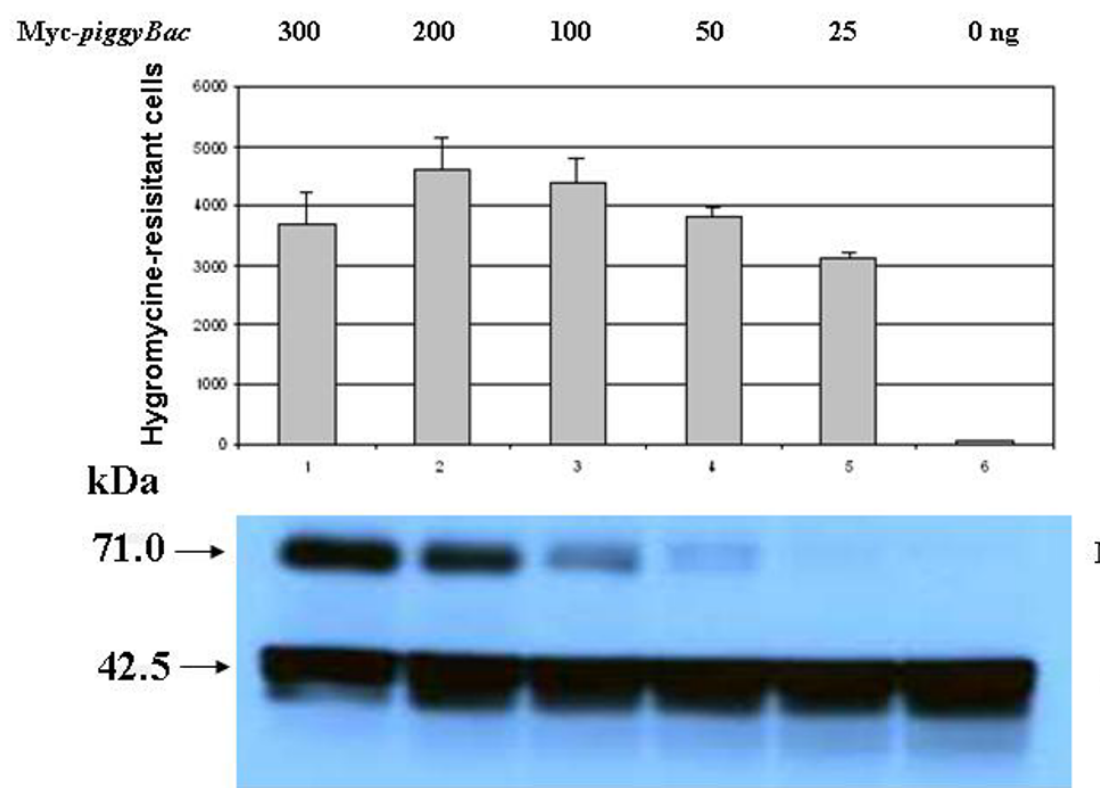

Myc-piggyBac

$\alpha$-actin

Figure 2 Transposition activity of various engineered Tol2 and piggyBac transposases. A. A schematic representation of tagged piggyBac and Tol2 transposases. B. The activity comparison between the wild-type and various epitope-tagged Tol2 and piggyBac transposases. C. The enzymatic activity of Myc-piggyBac. The enzymatic activity of Myc-piggyBac was measured under a fixed amount of pB-cassette3short (donor at $100 \mathrm{ng}$ ) co-transfected with increasing amounts of pCMV-Myc-piggyBac helpers (expressing the Myc-tagged piggyBac transposase) into HEK 293 cells. The lower panel depicts a Western blot indicating the expression level of the piggyBac transposase (detected by Myc antibody) and $\alpha$-actin (detected by $\alpha$-actin antibody) in the corresponding transfected cells. Western blotting was performed by isolating protein extracts from the remaining transfected cells of the same triplicate samples for the colony formation assay shown above. 
barely detected by Western blotting, 68\% of the transposition activity at its peak was still retained (compare lane 5 with lane 2 in Figure 2C), suggesting that piggyBac transposase is highly active.

\section{A global evaluation of Tol2 and piggyBac targeting preferences in the human genome}

Genome-wide target profiling of piggyBac and Tol2 in the human genome has been reported recently [33-36]. However, all these studies were based on data sets obtained by retrieving chromosomal targeting sequences from a mixed population of transposon targeted cells or using a PCR-based strategy. To fully explore their potential as mammalian genome manipulation tools for gene therapy and gene discovery, reliable data sets of target sequence preferences based on targeting sequences retrieved form independent integrants are needed for genome-wide target profiling of piggyBac and Tol2 in the human genome. In this regard, as for piggyBac, we co-transfected pXLBacII-cassette and pPRIGpiggyBac into HEK 293 cells. Likewise, Tol2ends-cassette and pPRIG-Tol2 were co-transfected into HEK 293 for Tol2. The transfected cells were subjected to colony formation under hygromycin selection at a low density enabling for isolating individual colonies without crosscontamination (see Methods for details). Hygromycinresistant colonies for piggyBac and Tol2 were individually cloned and further expanded. Genomic DNA isolated from individual clones was subjected to plasmid rescue for obtaining chromosomal DNA flanking the transposon insertion sites. We have isolated 164 and 114 individual colonies for Tol2 and piggyBac, respectively (Table 1). A total of 371 and 264 independent plasmids were respectively rescued from 142 Tol2 and 104 piggyBac colonies (Table 1) and subsequently sequenced. Only 149 and 315 of piggyBac and Tol2 targets resulted in a sequence of sufficient quality to execute a Blat search against the human genome database in the UCSC Genome Browser [37]. Among these, 107 piggyBac and 207 Tol2 targeting sequences had a strong match (over 95\% sequence identity) to human genomic sequences (Table 1).

Based on the established data sets (Table 1), we performed target profiling of piggyBac and Tol2 in the HEK 293 genome. Tol2 and piggyBac display non-overlapping targeting profiles, with targets scattered over the entire genome (Figure 3). Although Tol2 targets were detected in all 23 human chromosomes (HEK 293 lacks the Y chromosome due to its female origin), no piggyBac targets were found in chromosome 15 (Figure 3). Interestingly, clusters of Tol2 targets within a $10 \mathrm{~kb}$ interval are often detected (four clusters as circled in purple in Figure 3 and supplementary 1), whereas no such clusters are apparent for piggyBac. Tol2 predominately targets intergenic regions $(61.1 \%)$, whereas more than half of the piggyBac targets are located within known genes (51.6\%) (Figure 4A). With respect to intragenic targeting preferences, both piggyBac and Tol2 favorably target the introns of known genes and no piggyBac target is found within the ORF of a gene. Regarding the target distribution in the UTR region, piggyBac displays a skew towards the 3' UTR, while no such bias can be seen in Tol2 (Figure 4A). Finally, consistent with previous reports [33-35], both piggyBac and Tol2 have a significant bias for integrating close to $\mathrm{CpG}$ islands, as compared to the computer simulated random integrations, with a higher bias detected in piggyBac than in Tol2 (Figure 4A).

To measure the distributions of piggyBac and Tol2 targets with regards to the gene density around the target sites, we counted the number of genes located within a $200 \mathrm{~kb}$ interval on either side of their target sites. By this analysis, Tol2 tends to target to regions with lower gene densities, particularly favoring regions with one to two genes located within a $200 \mathrm{~kb}$ window on either side of the insertion site (Figure 4B).

We next determined the targeting preferences of piggyBac and Tol2 to different types of repeats in the human genome. Up to $51.2 \%$ of Tol2 targets were found within repeats, particularly LINEs (Figure 4C). The frequency of targeting to repeats by piggyBac was $31.8 \%$, with a slight preference for SINEs. No piggyBac targets were detected in Satellite and rDNA. Repetitive sequences are stretches of DNA with similar sequences, and are found in numerous locations in the genome. It is possible that if one transposon displays a lower degree of sequence constraints for targeting than the other one, it may be able to target repeats more frequently than the other one. Based on this assumption and the fact that the sequences flanking the 3' end are significantly more important than that flanking the $5^{\prime}$ end for both piggyBac and Tol2 target sites as determined by the sequence logo analysis detailed later (Figure 5A), we then applied sequence constraints to further address the

Table 1 The data sets of piggyBac and Tol2 genome-wide target profiling in HEK 293

\begin{tabular}{|c|c|c|c|c|c|}
\hline Transposon & $\begin{array}{l}\text { \# of individual } \\
\text { clones isolated }\end{array}$ & $\begin{array}{l}\text { successful rate in } \\
\text { plasmid rescue }\end{array}$ & $\begin{array}{l}\text { \# of individual } \\
\text { plasmid rescued }\end{array}$ & $\begin{array}{l}\text { \# of targets with a } \\
\text { quality sequence }\end{array}$ & $\begin{array}{l}\text { \# of targets mapped } \\
\text { to the human genome }\end{array}$ \\
\hline Tol2 & 164 & $86 \%(142 / 164)$ & 371 & 315 & 207 \\
\hline piggyBac & 114 & 91\% (104/114) & 264 & 149 & 107 \\
\hline
\end{tabular}

*: only the target sequences sharing $\geq 95 \%$ sequence identity with the corresponding human genome were selected 


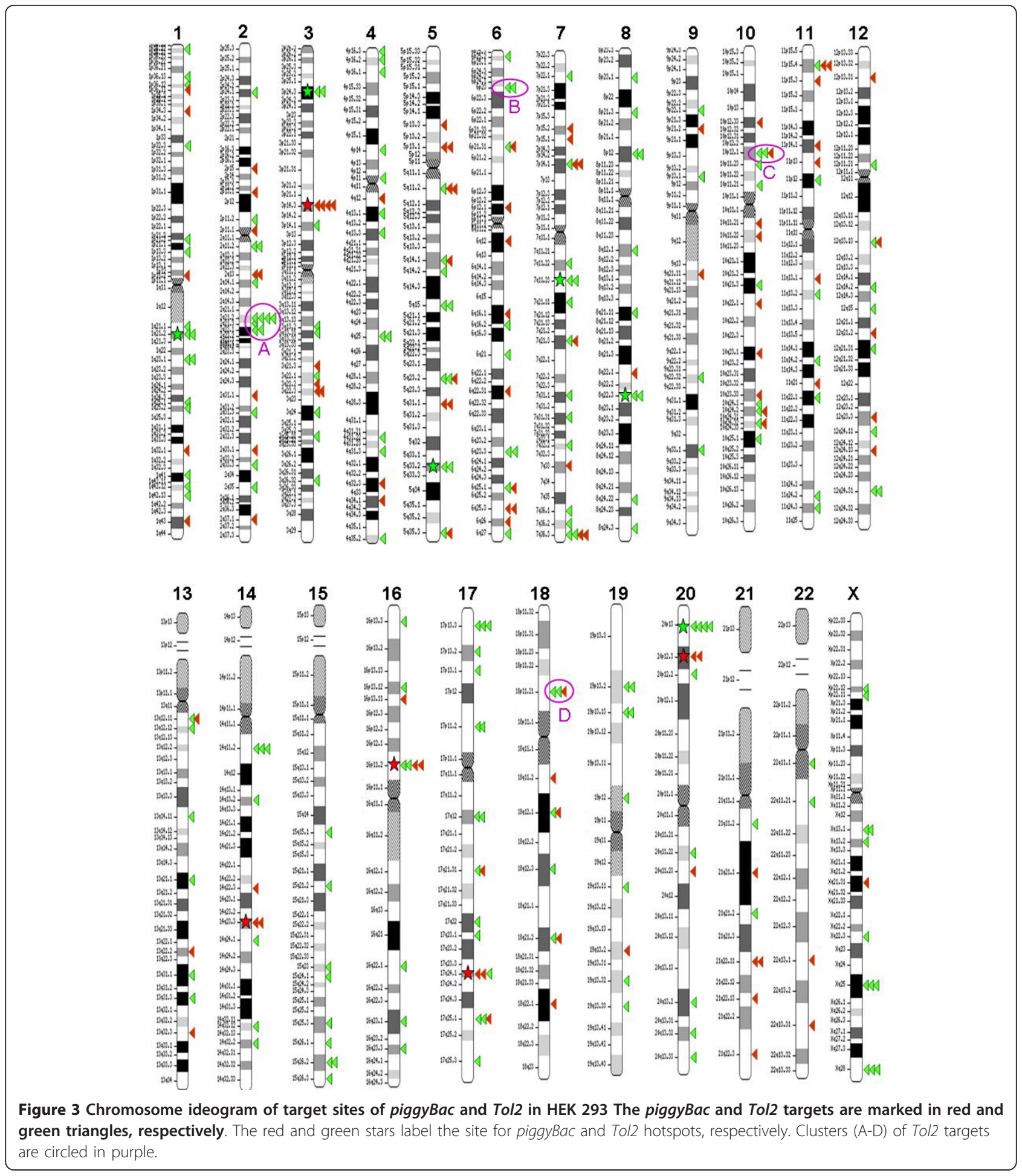

targeting pattern of both transposons to different repeats. In this analysis, we only counted the inserts located at the site within and more than $100 \mathrm{bp}$ upstream to the 3' end of targeted repeats (the lower part in each bar in Figure 4C). By applying this sequence constrain, the frequency of targeting repeats decrease much more dramatically in piggyBac than in Tol2 for the majority of repeat types (as compared the lower part of each bar to the whole bar in Figure 4C) suggesting that piggyBac may display a higher degree of sequence constrains than Tol2 in selecting their target sites. 
A.

B.
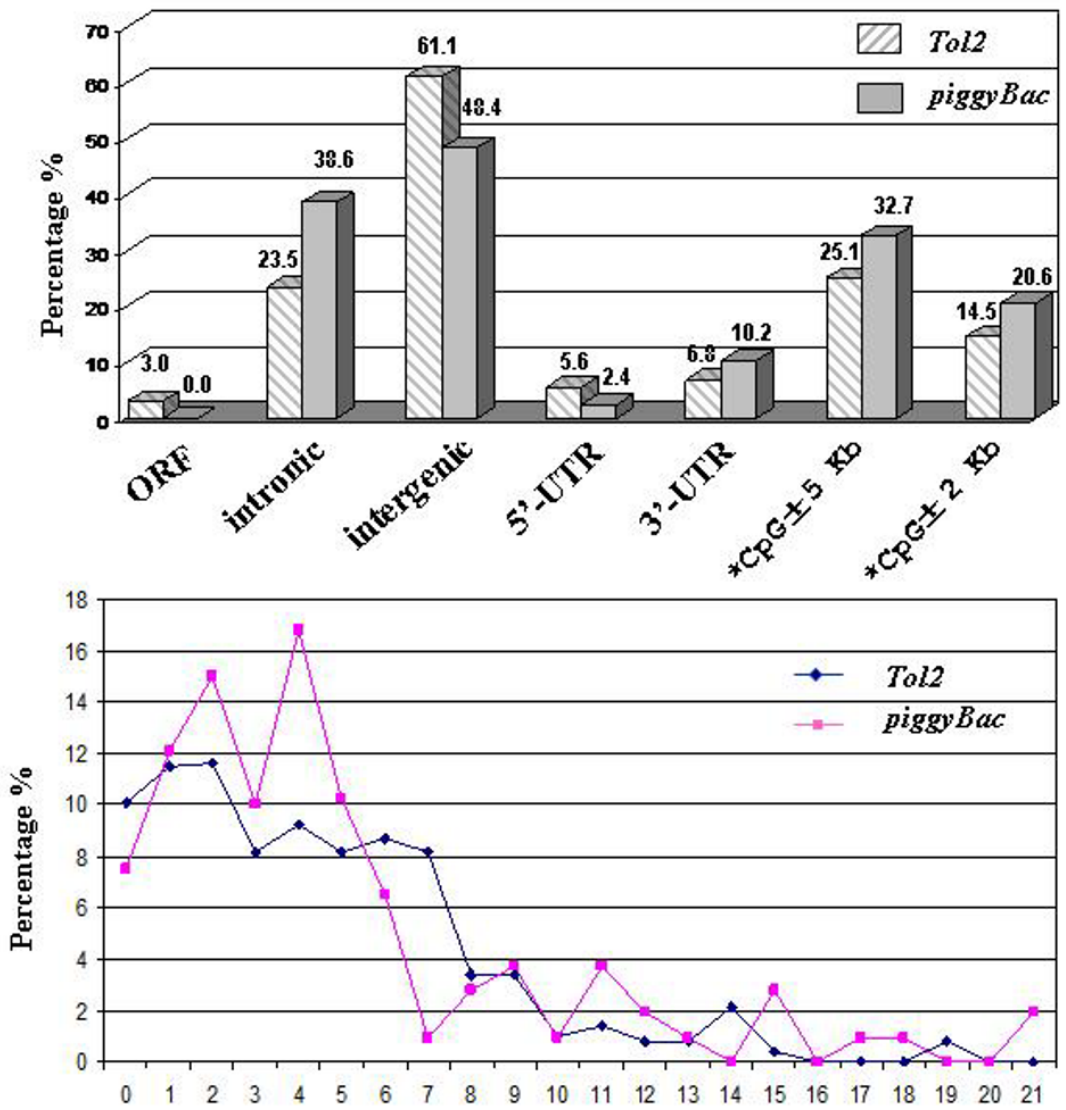

The total Number of genes within a $200 \mathrm{~kb}$ window on either side of the target site

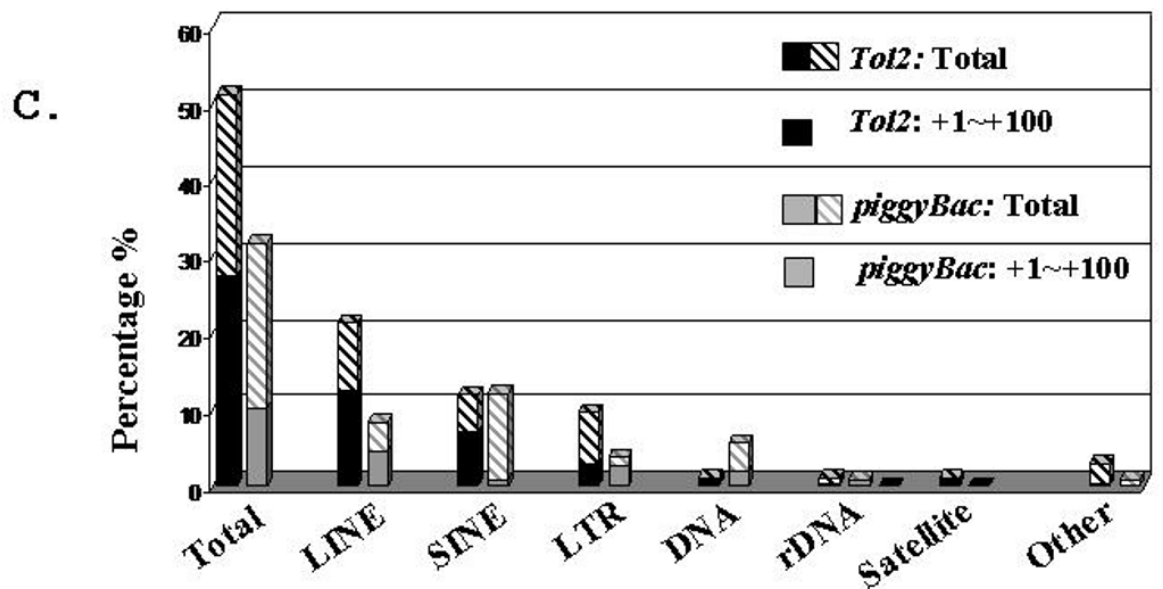

Figure 4 Preferential target sites of piggyBac and Tol2 transposons in HEK 293. A. The genome context of Tol2 and piggyBac target sites. * both transposons tend to insert near $\mathrm{CpG}$ islands more often than expected by chance (Tol2, $\mathrm{P}<10^{-9}$, piggyBac, $\mathrm{P}<10^{-11}$; see Methods). B. The gene density around Tol2 and piggyBac target sites. C. Distributions of piggyBac and Tol2 target sequences in various types of repeats. Every bar represents the percentage of target sites found in the type of repeats indicated. The bottom part of each bar represents the percentage of targets located within at least $100 \mathrm{bp}$ to the $3^{\prime}$ end of the repeats targeted. 
A.
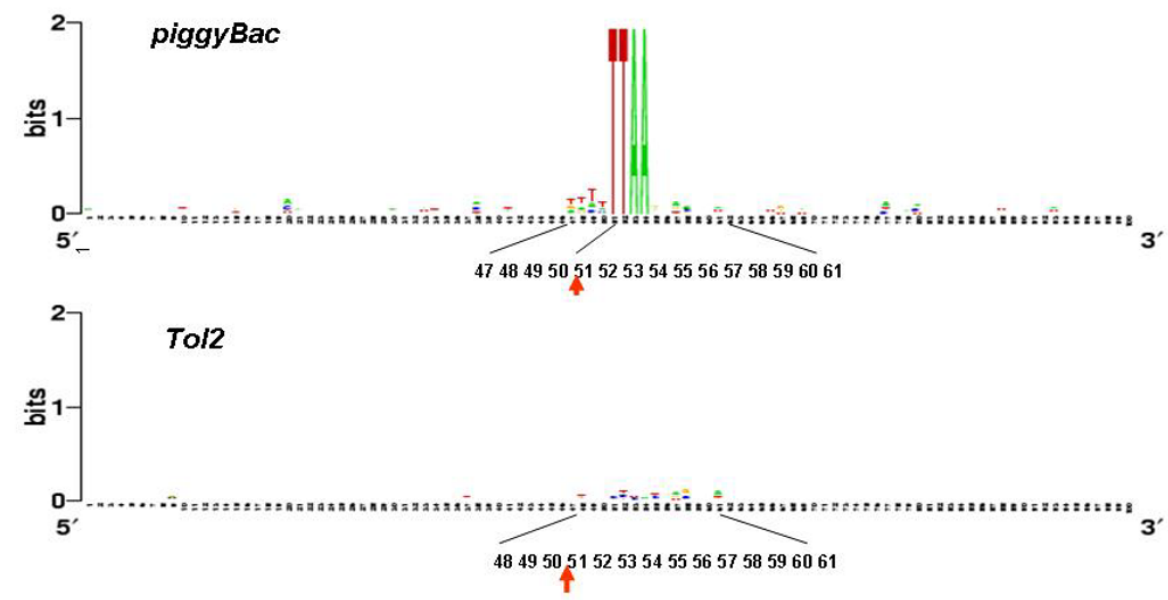

B.

Sepponceit B102-2B384; position chr14:66504521

-100 aattaaaataaattttaattttttattaaacagagctcggtgctaaaatctatggtcttgatatttgactcagtggggaaaggcaaaagattcattatt -1

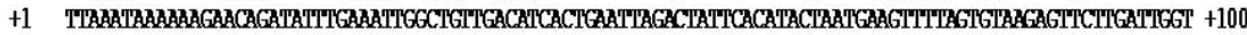

Sequonce it B92-1B75-4; position dr17.60391735

-100 ctttccaaaaatggaaatgcatttgaagacaataccaggcckttgaaaatgaagacgggagggtaaaaaacaagctgcaacagagaacagtatcaagctt -1

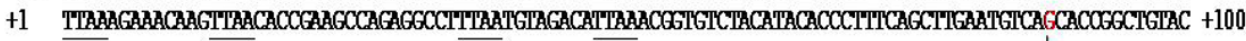
$\downarrow$ A at chr17: 63767669

C.
$\operatorname{chr} 16: 29493655$
Chr16:30232995
Chr16:29391412
$\begin{array}{lllll}-200 & -158 & -142 & -93 & +\end{array}$ $+1$ $+137+173+200$

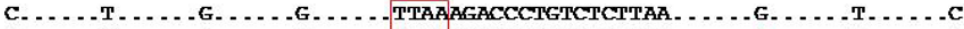 C. . . . . T . . . . . G. . . . . . G. . . . . . TTAAAGACCCTGTCTCTTAA. . . . . .A. . . . . . . . . . . . C

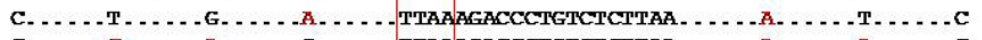 Chr16:21844686 C. . . . . C. . . . .A. . . . . . . . . . . TTAAAGACCCTGTCTCTTAA. . . . . ... . . . . ... . . . . .

D.
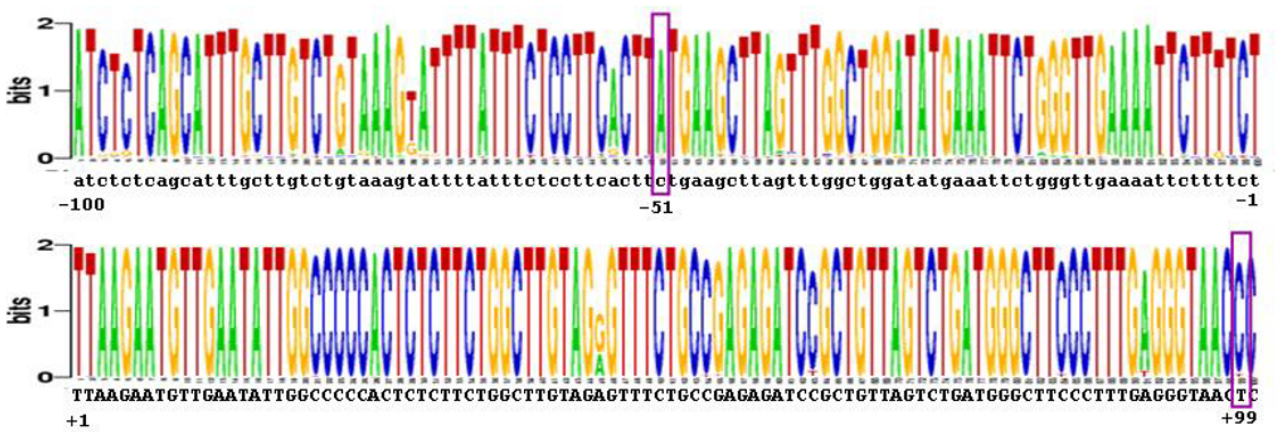

Figure 5 In-depth analyses of piggyBac and Tol2 target sequence preferences in HEK 293. A. The sequence logos of piggyBac and To/2 target sites. B. Two representative sequences flanking the sites repeatedly targeted by piggyBac. The TTAA tetranucleotide are underlined. C. A sequence alignment of four sequences on chromosome 16 that share 100\% sequence identity with the first 100 bp of the piggyBac target B89-4. The residue that is different from the other three sequences at a given position is indicated in red. Dots represent all the primary sequences that are identical in all four sequences. The numbers on the top indicate the relative position of residues. $D$. The sequence logo of 184 sequences that share at less $97 \%$ sequence identity with the piggyBac target, B87-4. Note: The chromosomal sequence $5^{\prime}$ and $3^{\prime}$ to the target site are in lower cases and upper cases, respectively. piggyBac transposon is inserted at the position between -1 and +1 . 
Sequence analyses of Tol2 and piggyBac target sites

To analyze the sequence preference for piggyBac and Tol2 targeting, we generated sequence logos for both transposon systems (Figure 5A). Consistent with previous reports, the characteristic TTAA tetranucleotide was exclusively found at the piggyBac target sites. Although no specific signature could be detected at Tol2 target sites, a weak but significant preference was observed in the first 10 11 bp 3' flanking the target site. Next, we searched for sites that are repeatedly targeted by either piggyBac or Tol2. Five and six sequences targeted repeatedly by piggyBac and Tol2, respectively, were identified (Table 2). And four out of 207 (1.9\%) independent Tol2 targeting events occurred at the same position located within the intron of signal-regulatory protein delta (SIRPD).

To further explore the nature of target site selection by piggyBac and Tol2, we performed a series of in-depth analyses on their target sequences. By conducting a Blat search against the UCSC genome browser database (assembly hg18) [37], we identified 16 piggyBac and 12 Tol2 targeting sequences which have at least the first 100 bp nucleotides 3' to the target site share more than $97 \%$ sequence identity with other sequences in the genome (Table 3). Surprisingly, 11 of the 12 Tol2 targets were located within repeats, but none of the 16 piggyBac targets was (Table 3). Again this observation may reflect a higher degree of sequence constrains in target site selection for piggyBac than for Tol2. Further analyses are required to reveal the nature of this discrepancy.
To study the nature of piggyBac target specificity, we next examined the neighboring sequences around five piggyBac hotspots. We observed that several TTAA tetranucleotides are located within a $100 \mathrm{bp}$ interval of two piggyBac hotspots. The target sequences in B102-2 and B38-4 are identical and contain three TTAA tetranucleotides within a $100 \mathrm{bp}$ interval upstream of the actual piggyBac TTAA target (Figure 5B). Similarly, the sequence of another piggyBac hotspot (as in B92-1 and B75-4), contains three TTAA tetranucleotides within the $100 \mathrm{bp}$ interval downstream of the genuine TTAA piggyBac target site. A Blat search has identified another sequence which is located $3.3 \mathrm{Mb}$ away and shares 99.5\% sequence identity with the target site of B92-1 and B75-4. As detailed in the lower sequence of Figure $5 \mathrm{~B}$, a $\mathrm{G}$ (in red) to A substitution is identified at +88 on the other sequence where the piggyBac target site is designated as 0 .

The fact that piggyBac targeted repeatedly to the same TTAA but not the adjacent TTAA tetranucleotides or to the TTAA site on another highly identical sequence nearby raise the possibility that the genuine TTAA piggyBac targets may be determined by some intrinsic sequence constraints flanking the target site. To further address this possibility, we focused on two other piggyBac target sequences, the B89-4 and B87-4 (Table 3). By a Blat search, we identified four sequences on chromosome 16 that share $100 \%$ sequence identity with one of the piggyBac hotspot as in B89-4 and B77-4 (Table 3). We then performed a multiple sequence alignment on

Table 2 The piggyBac and Tol2 hotspots in the HEK 293 genome

\begin{tabular}{|c|c|c|c|c|c|c|c|c|}
\hline Transposon & Target ID & Targeted sequence & Times & Position & $\begin{array}{c}\text { Gene } \\
\text { context }\end{array}$ & $\begin{array}{l}\text { Targeted } \\
\text { Gene }\end{array}$ & $\begin{array}{l}\text { Near gene } \\
\text { (distance } \\
\text { bp) }\end{array}$ & $\begin{array}{c}\text { Far gene } \\
\text { (distance } \\
\text { bp) }\end{array}$ \\
\hline \multirow[t]{5}{*}{ piggyBac } & $\mathrm{B} 87-5 / \mathrm{B} 89-3$ & TTAAATAAAGATAATAATACTAACCATGGCA & 2 & $3 p 14.3$ & INTRONIC & FLNB & & \\
\hline & B89-4/B77-4 & TTAAAGACCCTGTCTCTTAAAAAAAAAAAAA & 2 & $16 \mathrm{p} 11.2$ & 3'UTR & MLAS & & \\
\hline & B38-4/B102-2 & ПTAAATAAAAAAGAACAGATATTGAAATTG & 2 & $14 q 23.3$ & INTRONIC & GPHN & & \\
\hline & B71-1/B109-3 & TTAAATTCCAGGTITCTCAAAGAAAGCTTGT & 2 & 20p12.3 & INTERGENIC & & $\begin{array}{l}\text { BC043288 } \\
(219296)\end{array}$ & $\begin{array}{c}\text { BMP2 } \\
(347908)\end{array}$ \\
\hline & B75-4/B92-1 & TTAAAGAAACAAGTTAACACCGAAGCCAGAG & 2 & $17 q 24.1$ & INTERGENIC & & $\begin{array}{l}\text { FLJ32065 } \\
(2686)\end{array}$ & $\begin{array}{c}\text { LRRC37A3 } \\
(101620)\end{array}$ \\
\hline \multirow[t]{6}{*}{ Tol2 } & $\mathrm{T} 47-2 / \mathrm{T} 48-3$ & TGTTCCGCTCCTGGTGCGGGCCGAGACCCGG & 2 & $1 \mathrm{q} 21.2$ & INTRONIC & ZNF687 & & \\
\hline & $111-2 / \top 119-1$ & TATGTGTAATAATGGAGGTATGTACAACAT & 2 & $3 p 24.3$ & INTERGENIC & & $\begin{array}{l}\text { SGOL1 } \\
(385347)\end{array}$ & $\begin{array}{l}\text { HPX-42 } \\
(834010)\end{array}$ \\
\hline & $\mathrm{T} 14-3 / \mathrm{T} 17-1$ & AGAATAGGTATITCTIIITTCTTCTTATC & 2 & $5 q 33.2$ & INTERGENIC & & $\begin{array}{l}\text { C5orf3 } \\
(87465)\end{array}$ & $\begin{array}{l}\text { GRIA1 } \\
(92385)\end{array}$ \\
\hline & $\mathrm{T} 2-1 / \mathrm{T} 3-2$ & TCCACCACAGCATGAGTTAAACCAAAGTCT & 2 & $7 q 11.23$ & INTERGENIC & & $\begin{array}{l}\text { POMZP3 } \\
(2680)\end{array}$ & $\begin{array}{l}\text { hPMSR6 } \\
(350693)\end{array}$ \\
\hline & $\mathrm{T} 1-3 / \mathrm{T} 4-1$ & CCTGCCCAGCTCGTAAAAGGATGCTCACCT & 2 & $8 q 22.3$ & INTERGENIC & & GRHL2 (694) & $\begin{array}{l}\text { NACAP1 } \\
(122197)\end{array}$ \\
\hline & $\begin{array}{l}\text { TB7-3/T113-1/ } \\
\text { T115-4/Т120-2 }\end{array}$ & AATTTATCCATTTCTTCTAGATTTTCTAGT & 2 & 20p13 & INTRONIC & SIRPD & & \\
\hline
\end{tabular}


Table 3 The piggyBac and Tol2 targets located within the repetitive sequences of the HEK 293 genome

\begin{tabular}{|c|c|c|c|c|c|c|c|c|}
\hline \multirow[t]{2}{*}{ Transposon } & \multirow{2}{*}{$\begin{array}{l}\text { Representative } \\
\text { targets }\end{array}$} & \multirow[t]{2}{*}{ Sequence $(+1 \sim+30)$} & \multirow[t]{2}{*}{ Position } & \multicolumn{3}{|c|}{ Sequence identity } & \multirow{2}{*}{$\begin{array}{l}\text { Types of } \\
\text { repeats }\end{array}$} & \multirow{2}{*}{$\begin{array}{c}\text { Times } \\
\text { targeted }\end{array}$} \\
\hline & & & & $100 \%$ & $\begin{array}{r}99.9 \% \\
\sim 97.0 \% \\
\end{array}$ & Total & & \\
\hline \multirow[t]{16}{*}{ piggyBac } & B89-4 & TTAAAGACCCTGTCTCTTAAAAAAAAAAAA & $\begin{array}{c}\text { chr16 } \\
\text { (30140496) }\end{array}$ & 4 & 0 & 4 & $\mathrm{NF}$ & 2 \\
\hline & B87-4 & TTAAGAATGTTGAATATTGGCCCCCACTCT & $\begin{array}{c}\text { chr3 } \\
(55059477)\end{array}$ & 1 & 510 & 511 & $\mathrm{NF}$ & 1 \\
\hline & B75-4 & TTAAAGAAACAAGTTAACACCGAAGCCAGA & $\begin{array}{c}\text { chr17 } \\
(60391785)\end{array}$ & 1 & 1 & 2 & $\mathrm{NF}$ & 2 \\
\hline & B85-4 & TTAAAAAAGGCATTATTITCGCAGCTATCT & $\begin{array}{c}\text { chr6 } \\
(125167100)\end{array}$ & 0 & 2 & 2 & $\mathrm{NF}$ & 1 \\
\hline & B42-3 & TTAATTACTTAAGATAATGGCCTCCACAC & $\begin{array}{c}\text { chr22 } \\
(15414966)\end{array}$ & 5 & 3 & 8 & $\mathrm{NF}$ & 1 \\
\hline & B100-1 & TTAAGAAAGGAGTTGAATTAAGCTCAGGTT & $\begin{array}{c}\text { chr1 } \\
\text { (120900969) }\end{array}$ & 0 & 2 & 2 & $\mathrm{NF}$ & 1 \\
\hline & B90-1 & TTAATATCCCACCTTIGCACAGTAGACAAT & $\begin{array}{c}\text { chr3 } \\
\text { (137392502) }\end{array}$ & 2 & 0 & 2 & $\mathrm{NF}$ & 1 \\
\hline & B92-2 & TTAAACACACACTTAGAGGGAAATAATTCAT & $\begin{array}{c}\text { chr18 } \\
\text { (11877795) }\end{array}$ & 0 & 2 & 2 & NF & 1 \\
\hline & B82-3 & TAAAGAATATAAGGCCAAGCACAGTGGCT & $\begin{array}{c}\text { chr11 } \\
(27402368)\end{array}$ & 1 & 1 & 2 & $\mathrm{NF}$ & 1 \\
\hline & B89-3 & TTAAATAAAGATAATAATACTAACCATGGC & $\begin{array}{c}\text { chr3 } \\
\text { (57972969) }\end{array}$ & 1 & 1 & 2 & $\mathrm{NF}$ & 1 \\
\hline & B92-1 & TTAAAGAAACAAGTTAACACCGAAGCCAGA & $\begin{array}{c}\text { chr17 } \\
(60391785)\end{array}$ & 2 & 2 & 4 & $\mathrm{NF}$ & 1 \\
\hline & B77-4 & TTAAAGACCCTGTCTCTTAAAAAAAAAAAA & $\begin{array}{c}\text { chr16 } \\
\text { (29401156) }\end{array}$ & 0 & 4 & 4 & $\mathrm{NF}$ & 1 \\
\hline & B79-2 & TTAAGGGGGGAAAACAGTTCAGGGCCAACA & $\begin{array}{c}\text { chr14 } \\
\text { (55711916) }\end{array}$ & 1 & 1 & 2 & $\mathrm{NF}$ & 1 \\
\hline & B84-1 & TTAATGTTAAATTACAAACACTGTTTTATC & $\begin{array}{c}\text { chr18 } \\
(29434150)\end{array}$ & 0 & 2 & 2 & $\mathrm{NF}$ & 1 \\
\hline & B85-1 & TTAAGCACAGTATCAGTGATAAAAATAGCT & $\begin{array}{c}\text { chr1 } \\
\text { (201276407) }\end{array}$ & 1 & 1 & 2 & $\mathrm{NF}$ & 1 \\
\hline & B82-1 & TTAAGCTGAATCTGTITTCCCAGTGCCCC & $\begin{array}{c}\text { chr2 } \\
\text { (231461932) }\end{array}$ & 0 & 2 & 2 & $\mathrm{NF}$ & 1 \\
\hline \multirow[t]{12}{*}{ Tol2 } & T111-3 & TTAAGAATGTTGAGTATTGGCCCCCACTC & $\begin{array}{c}\text { chr8 } \\
(9712455)\end{array}$ & 1 & 8 & 9 & LINE & 1 \\
\hline & T147-1 & ATCCTGAGCAGCCGAATCTGCAATCATCTT & $\begin{array}{c}\text { chr7 } \\
\text { (154665283) }\end{array}$ & 1 & 1 & 2 & LTR & 1 \\
\hline & T3-2 & TCCACCACAGCATGAGTTAAACCAAAGTCT & $\begin{array}{c}\text { chr7 } \\
\text { (76097237) }\end{array}$ & 2 & 0 & 2 & LINE & 1 \\
\hline & T88-3 & GTCTGTACTGCTGCAAAGCTTCACAGACAG & $\begin{array}{c}\text { chr10 } \\
\text { (98485313) }\end{array}$ & 1 & 2 & 3 & NF & 1 \\
\hline & T115-4 & AATTTATCCATTTCTTCTAGATTTTCTAGT & $\begin{array}{c}\text { chr20 } \\
(1472025)\end{array}$ & 0 & 3 & 3 & LINE & 4 \\
\hline & T103-2 & GGCGCCCGCCACTACGCCTGGCTAATTाT & $\begin{array}{c}\text { chr21 } \\
\text { (13847935) }\end{array}$ & 1 & 3 & 4 & SINE & 1 \\
\hline & T162-3 & CCAGAGACCTTTGTCACTTGTTAATCTGC & $\begin{array}{c}\text { chr20 } \\
\text { (33206406) }\end{array}$ & 202 & ND & $\begin{array}{c}> \\
202\end{array}$ & Low_complexity & 1 \\
\hline & T157-1 & CTCGTACGTAAGTITAGTGTGAACATATA & $\begin{array}{c}\text { chr4 } \\
\text { (48956277) }\end{array}$ & 4 & 3 & 7 & LINE & 1 \\
\hline & T157-2 & GTTAACAGTGACCTATTGGGAGAAGGGGA & $\begin{array}{c}\text { chr7 } \\
\text { (66290199) }\end{array}$ & 1 & 1 & 2 & LINE & 1 \\
\hline & T107-2 & AATATATGAGTAGCTAAACAACTCTATAAG & $\begin{array}{c}\text { chr2 } \\
(97613844)\end{array}$ & 1 & 1 & 2 & LINE & 1 \\
\hline & T104-1 & GAACACATGGACACAGGAAGGGGAACATCA & $\begin{array}{c}\text { chr3 } \\
\text { (134171282) }\end{array}$ & 1 & 52 & 53 & LINE & 1 \\
\hline & $\mathrm{T} 25-3$ & ACCCCATCTCTACTAAAAATACAAAAAATT & $\begin{array}{c}\text { chr6 } \\
\text { (166733349) }\end{array}$ & 1 & 1 & 2 & SINE & 1 \\
\hline
\end{tabular}


these four sequences. Although the primary sequence of these four sequences with a 200-bp interval on either side of the TTAA target site is almost identical, both B89-4 and B77-4 target to the same TTAA tetranucleotide on the top but not the other three similar sequences in Figure 5C. Another example, B87-4, was found to share at least $97 \%$ sequence identity with 510 sequences elsewhere in the human genome, yet none of these highly similar sequences were targeted by piggyBac (Table 3). To gain further insight into the nature of piggyBac target selection, we retrieved the top 184 sequences that share $99 \%$ sequence identity with the first $100 \mathrm{bp}$ of the B87-4 target. As revealed by the sequence logo analysis, the primary sequence of these 184 sequences is highly conserved (Figure 5D). By designating the first $\mathrm{T}$ of TTAA as +1 , the conserved $\mathrm{A}$ at -51 and $C$ at +99 are changed to $C$ and $T$, respectively, in the B87-4 target. Collectively, these observations strongly suggest that piggyBac does not target arbitrarily to any TTAA tetranucleotide in the human genome but rather to the TTAA sites in a specific sequence context.

\section{The activity of genes nearby the piggyBac and Tol2 hotspots}

Genome-wide targeting analyses of retroviruses have revealed their biased nature in preferentially targeting to active regions of the host chromatin. To address whether gene activity had an influence on target preferences of piggyBac and Tol2, we performed quantitative RT-PCR (Q-RT-PCR) analyses, focusing mainly on genes located within or within a $10 \mathrm{~kb}$ interval from either Tol2 or piggyBac hotspots. The house keeping gene GAPDH and three neural genes with a broad range of expression levels in HEK 293 [38] were selected to serve as references for Q-RT-PCR analyses. It is impossible to assess the relative abundance of difference genes by directly comparing the Q-RT-PCR signal between various primer pairs. Hence, we designed the primer pair within the same exon for each gene. The expression level for each gene was then evaluated by the ratio of the relative copy number derived from Q-RTPCR and that derived from quantitative PCR (Q-PCR) by using the same primer pair on mRNA and the genomic DNA of HEK 293, respectively. Most of the genes tested were either not expressed or expressed at a much lower level as compared to GADPH (Figure 6). Notably, SIRPD, the gene containing the most frequently targeted Tol2 hotspots was barely expressed in HEK 293 (Figure 6). Hence, it is highly likely that gene activity has no influence on the hotspot selection of piggyBac and Tol2. Indeed we have recently identified a piggyBac hotspot located at a gene that is silenced in HEK 293 (Meir et. al., unpublished observation).
Risk assessment of targeting within or near cancerrelated genes by piggyBac and Tol2

Random insertion mutagenesis is a real threat to gene therapy [39]. The mutagenic potential caused by random insertions of any transposon remains the greatest concern for their advancement to clinical applications. In this regard, we assessed the risk of Tol2 and piggyBac for their potential of inducing oncogenesis by counting the number of piggyBac or Tol2 targets located either directly within or within a defined distance of a cancerrelated gene. The frequency of targeting to sites within either a $400-\mathrm{kb}$ or $1000-\mathrm{kb}$ distance from cancer-related genes was significantly higher in piggyBac than in Tol2 (Figure 7). However, the frequency of targeting within a cancer-related gene was higher in Tol2 than in piggyBac (Figure 7). Cancer related genes targeted by Tol2 or piggyBac are listed in Table 4. Notably, piggyBac targeted twice to the same site within one particular cancerrelated gene, gephyrin (GPHN), raising a great concern for its safe use in gene therapy [40-42].

\section{Discussion}

The longer the foreign sequences introduced into the host genome, the greater the probability of evoking adverse consequences, such as transgene silencing and dysregulation of the endogenous genes nearby. Hence, for both basic research and clinical applications, a transposon system with smallest terminal repeats for genetic manipulations is desired. By removing most of the nonfunctional sequences of piggyBac and Tol2 TRDs, we observed a 1.5- and 3.3-fold increase in transposition activity for piggyBac and Tol2, respectively. The increase in transposition activity for both piggyBac and Tol2 is unlikely to be due to their reduction in size, since the piggyBac element in the pXLBacII-cassette and the Tol2 element in the Tol2ends-cassette are both within their maximal cargo capacity of $9.1 \mathrm{~Kb}$ and $10 \mathrm{~Kb}$, respectively [14,22]. In general, the transposition activity of a transposon negatively correlates with the fitness of the host. Although in most cases the activity of transposons in the host is abolished due to mutations and deletions, some transposons are intact but are completely silenced epigenetically by host defense mechanisms [43]. For example, RNAi is the mechanism for silencing the Tc1 DNA transposon in the germ line of Caenorhabditis elegans [44]. Unlike pXL-BacII-cassette only consisting of 245 bp-left and 313 bp-right TRD, the Tol2end-cassette preserves most of the non-coding cis sequences of the wild-type Tol2 transposon. These "non-essential sequences" may be susceptible to epigenetic silencing and in turn attenuate their transposition activity. This possibility may explain why extra cis sequences in Tol2ends-cassette has a greater impact in deregulating 


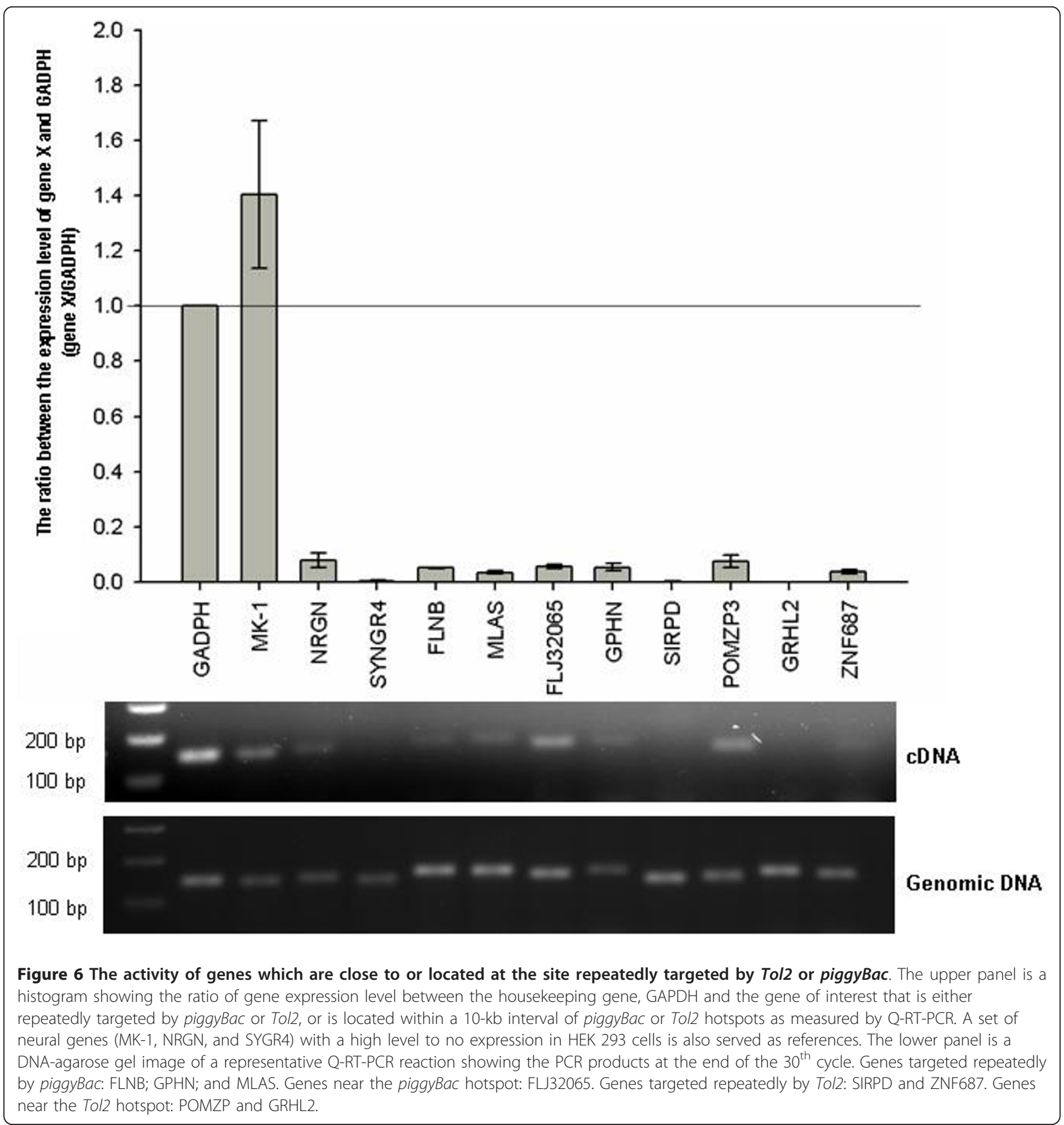

transposition activity than that of pXLBacII-cassette. This observation further implicates the possible interaction between epigenetic silencing factors and the cis sequence of wild-type transposons, and for Tol2 in particular. Studies are now underway to address this possibility.

Unlike our findings that $\mathrm{pPB}$-cassette3short with short TRDs at the ends results in a higher activity than its long counterpart in HEK 293, attempts to transform $D$. melanogaster with $\mathrm{p}(\mathrm{PZ})$-Bac-EYFP consisting of 35-bp 3'TRD and 63-bp 5'TRD yielded transformation frequencies far less than full-length piggyBac constructs (reduced from 15\% to 0.6\%) [29]. This discrepancy may simply reflect the differences in the components and/or the mechanism involved in transposition between mammalian and insect cells. It is also possible that the extra 5 and 4 nucleotides included in our 3 ' - and 5'-TRD, respectively, are crucial for an effective transposition. 


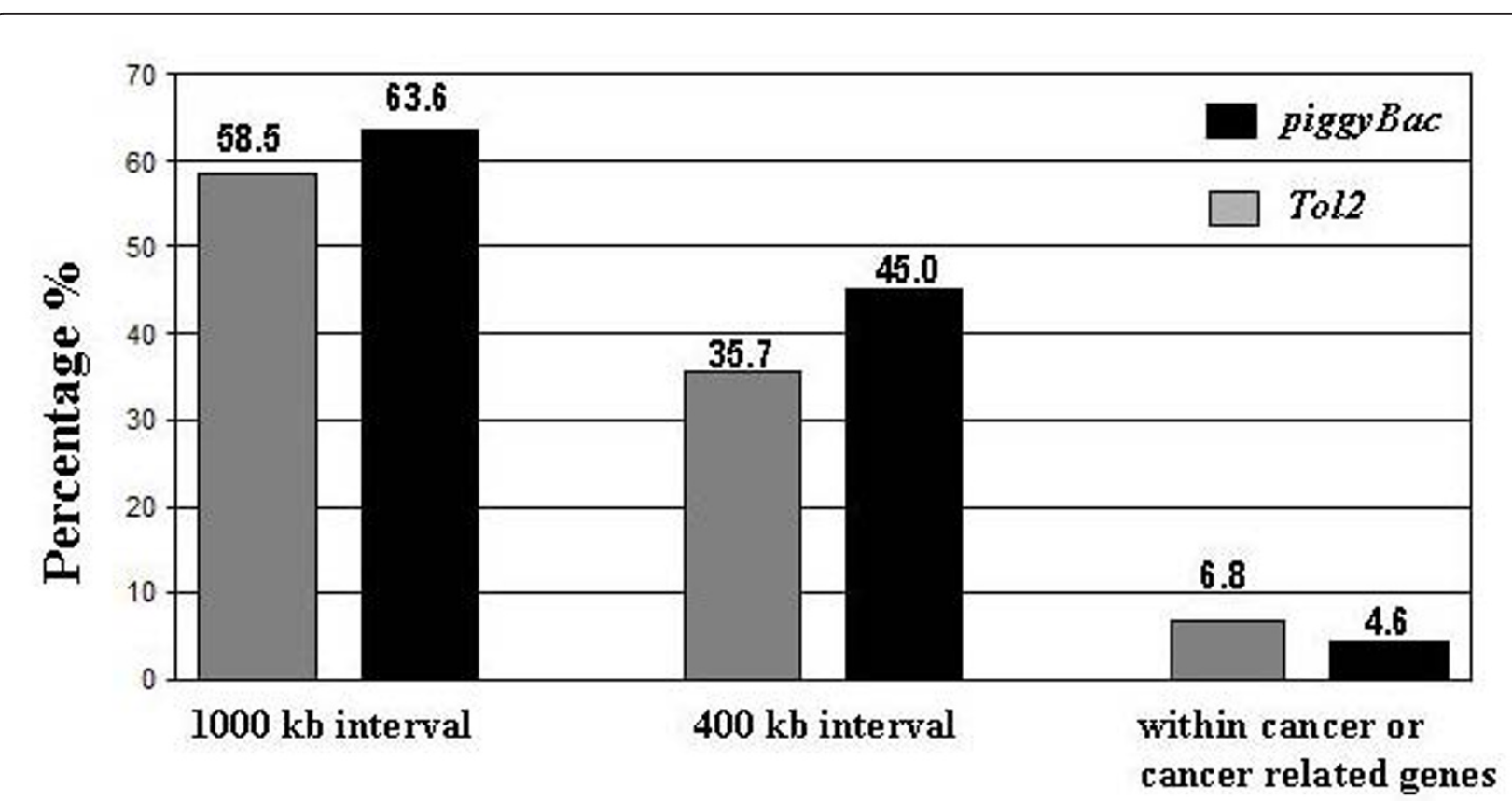

Figure $7 \mathrm{~A}$ risk evaluation of piggyBac and Tol2 for targeting to the region located within or near cancer related genes in a genomewide scale. The histogram shows the percentage of piggyBac or Tol2 targets located within or within a defined distance away from cancerrelated genes.

Table 4 A list of cancer-related genes targeted by iggyback or Tol2

\begin{tabular}{|c|c|c|c|c|}
\hline Transposon & $\begin{array}{c}\text { Target } \\
\text { ID }\end{array}$ & Sequence & $\begin{array}{c}\text { Targeted } \\
\text { Cancer Gene } \\
\end{array}$ & Annotation \\
\hline \multirow[t]{6}{*}{ piggyBac } & B102-2 & TTAAATAAAAAAGAACAGATATTTGAAATTGGCTGTTG & GPHN & gephyrin \\
\hline & B107-3 & TTAATGATTCTTTCCATTTCTTTTATTCTTTTCCTAGC & HHEX & hematopoietically expressed homeobox \\
\hline & B27-3 & TTAATAGAAAGGAAGGGACCATGTTAAACATAAATGCT & POU6F2 & POU class 6 homeobox 2 \\
\hline & B38-4 & TTAAATAAAAAAGAACAGATATTTGAAATTGGCTGTTG & GPHN & gephyrin \\
\hline & B63-1 & TAAAGTTTCAGTGGCTGAAAGTTGGCAGTCTGAAAAA & ARF4 & ADP-ribosylation factor 4 \\
\hline & B81-1 & TTAAGTGCTTTTGGCTGTTTTCCCAAACATCCAGACAT & SMAD5 & SMAD family member 5 \\
\hline \multirow[t]{17}{*}{ Tol2 } & $\mathrm{T} 12-2$ & GGTAGGAGTTATCTGAGTCAGGCCTGCCCTTGGCTTGG & SPECC1 & cytospin B \\
\hline & T121-1 & CTCCTGGGTGACCCTCGCCTGAGCCTCCTGGCCCTTCC & RAB40B & RAB40B, member RAS oncogene family \\
\hline & T102-4 & GACACAAACACACACATGCTATACCTTTGTATTACACT & TCF4 & transcription factor 4 \\
\hline & T124-4 & GCGGCTGTCCTCCAGCAACAGGTGCACATTCCCGGGCT & TNK1 & tyrosine kinase, non-receptor \\
\hline & $\mathrm{T} 130-2$ & CAAATAAATGAATGTTATGAATTITGAGGGTAGGAAA & SEMA3C & $\begin{array}{l}\text { sema domain, immunoglobulin domain (lg), } \\
\text { (semaphorin) } 3 \text { C precursor }\end{array}$ \\
\hline & T137-3 & AAAGAGAGGCCCAATCCTGTGGAGTGAGTCACTGGGGG & ALPL & alkaline phosphatase, liver/bone/kidney \\
\hline & $\mathrm{T} 137-4$ & ATTITCTGTCTGCTCTTTGGTCACTTCCCATTCTITTT & PARD3 & $\begin{array}{c}\text { par-3 partitioning defective } 3 \text { homolog (C. } \\
\text { elegans) }\end{array}$ \\
\hline & T157-4 & TTATTTGTCCTGCACTTATGAAGCATAGTTTGGCAGG & PGR & progesterone receptor \\
\hline & T165-1 & GAAACCGGCGAAAAGGTTAGCTGTCGCTGGCTAGTATT & RASSF3 & $\begin{array}{c}\text { Ras association (RalGDS/AF-6) domain family } \\
\text { member } 3\end{array}$ \\
\hline & $\mathrm{T} 22-1$ & TTCCTAAGCTACAATAAACCACATATGAAAAACTAAAG & $\mathrm{HD}$ & huntingtin \\
\hline & T26-1 & AGCCTGAGTAAAATAGTGAGACTCTGTTTCTGCAAAAC & LRP1B & low density lipoprotein-related protein 1B \\
\hline & T43-3 & TCTGGAAGGTGAGGCAGACGTGCCCACCGCCTCCATGC & HLXB9 & motor neuron and pancreas homeobox 1 \\
\hline & T91-4 & TTCAGGGGGTGTGTTGGAGGGGAATCGCCGGCCTGCCT & $1 \mathrm{HH}$ & Indian hedgehog homolog (Drosophila) \\
\hline & TB7-5 & AATTTATCCATTTCTTCTAGATTTTCTAGTTTATTCGC & FKBP1A & FK506 binding protein 1A, 12kDa \\
\hline & TB70-1 & GTGCACACACTCACTCTCTCTITCTCCTTCAGATAATA & FOXP1 & forkhead box P1 \\
\hline & TB77-2 & СCCCTCACCCTCGGACCCTTCACCGCGACCCCCGCGCC & RANBP9 & RAN binding protein 9 \\
\hline & TB81-1 & TGCAGTACAGTGCGGGGGGAAAAAAACAACAGCAAAAG & EGF & epidermal growth factor (beta-urogastrone) \\
\hline
\end{tabular}


Another important feature of our functional piggyBac terminal sequences (referred as micro-PB hereafter) is that most of the activator sequences (as underlined in Figure 1A) identified previously in D. melanogaster [45] are excluded. In this respect, the micro-PB may potentially be a safer cis-piggyBac element as a mammalian genetic tool as compared to the minimal piggyBac cissequence identified previously. Studies are now underway to address whether micro-PB exhibits any enhancer or silencer activity.

Genome-wide targeting profiles of piggyBac and Tol2 in the human genome have been previously reported [31-34]. All of these analyses utilized chromosomal target sequences that were retrieved either by plasmid rescue from a heterogenous population of targeted cells or by PCR-based strategies using a limited amount of genomic DNA isolated from individual targeted clones grown on 96-well plates. Several factors may introduce strong biases into the data sets obtained in these studies including (1) differences in proliferation rates of the individual targeted cells, (2) intrinsic difficulties in retrieving certain targeting sequences, and (3) biases in obtaining PCR products from certain templates but not from the others. Hence, to fully evaluate the pros and cons of piggyBac and Tol2 for gene discovery and gene therapy, a direct comparison of their genome-wide targeting profile based on reliable data sets obtained within the same experimental setting was needed. To achieve this goal, we utilized a labor intensive strategy involving isolating, expending, and performing plasmid rescue to retrieve chromosomal targeting sequences for each individual HEK 293 clone targeted. Based on the following observations, we believe the data sets established in this study provides reliable insights into the targeting profiles of piggyBac and Tol2. First, we successfully rescued plasmids from $87 \%$ and $91 \%$ of piggyBac and Tol2 targeted clones, and the majority of clones that were not rescued were due to a lack of sufficient genome DNA for performing plasmid rescue. Second, several copies of an identical plasmid were often obtained in the same targeted clones, suggesting that most, if not all, inserts in the same clones were successfully recovered. Third, for each individual clone targeted, we normally obtained 14 different inserts, consistent with a recent report that the copy number of Tol2 and piggyBac in HeLa cells ranges between 1-3 and 1-4, respectively [34]. Identifying targeted sites in individual clones has led to the identification of piggyBac and Tol2 hotspots and allowed us to perform a detailed and unbiased analysis on target site preferences for both transposon systems.

All piggyBac and Tol2 hotspots identified in this study are likely to be bona fide given the following reasons. First, the protocol (as detailed in the methodology section) used to isolate individual targeted clones is intentionally designed to avoid cross-contamination between individual drug-resistant colonies. Second, all of the target sequences in this study were retrieved using plasmid rescue rather than a PCR-based strategy. A small amount of contaminating genomic DNA, if any, is not sufficient for a successful plasmid rescue. Third, the four Tol2 targets mapped to the hotspot located in the SIRPD locus were derived from two separate experiments suggesting the occurrence of independent targeting events at this particular site in the HEK 293 genome. Finally, all of the piggyBac and Tol2 clones with a hotspot targeted contain additional integrations mapped to distinct chromosomal locations (data not shown), indicating all of these targeted clones were indeed independent. Our analyses of Tol2 have revealed a distinct global targeting distribution among 23 human chromosomes in HEK 293, which stands in sharp contrast to the reported Tol2 distribution in HeLa cells (compare Figure 4 with the Figure 6A in reference 34). Distinct Tol2 genome-wide targeting profiles in HEK 293 and HeLa cells seem to reflect their difference in frequency of targeting to different genomic contexts. For instance, our analyses revealed $23.5 \%$ and $15.4 \%$ of Tol2 intronic and exonic targeting frequency in HEK 293, respectively (Figure 5A), while the reported intronic and exonic targeting rate of Tol2 in HeLa cells are $45.1 \%$ and 3.5\%, respectively (Table 2 in reference 34). Discrepancies in the frequency of Tol2 targeting to various repeat types between our study and others were also detected. Two factors may account for the observed discrepancies: namely (1) differences in strategies, and (2) differences in Tol2 targeting preferences in HEK 293 and HeLa cells. The former factor should not substantially contribute to the great difference in targeting preferences seen in the two separate studies, since even if one approach is less biased than the other, a certain degree of overlapping in Tol2 target distributions should still be detected in both human cell types. However, this is not the case. Hence, the non-overlapping Tol2 target profiles are likely due to differences in cell types. As for piggyBac, although its intragenic target rate in this study (51.6\% in HEK 293) and in other studies (51.9\% in primary $\mathrm{T}$ cells) is similar, we observed a much higher frequency of piggyBac targeting to untranslated regions in HEK 293 (15.8\% total) than what was observed in primary $\mathrm{T}$ cells $(1.7 \%$ total) (compare Figure $5 \mathrm{~A}$ with data reported in reference 35). Additionally, we fail to detect any piggyBac targets that are found both in HEK293 (this study) and in human $\mathrm{T}$ cells [35]. Unlike the data set established in this study, the genome-wide piggyBac targets in primary T-cells were obtained from a heterogenous population of piggyBac targeted clones [35]. Consequently, the data set obtained from primary $\mathrm{T}$ cells is inevitably biased to the target sites that are easily 
retrieved by plasmid rescue, a factor that may contribute significantly to the sharp contrast in the targeting profiles of piggyBac observed in the two different cell types. However, our data set revealed five piggyBac hotspots in HEK 293 and yet no target in our data set is found in that of primary $\mathrm{T}$ cells, suggesting cell type differences may still be the major contributing factors when explaining these observed differences. Furthermore, these differences were likely to be amplified by the fact that unlike T-primary cells which contain normal 46 chromosomes, HEK 293 is a transformed cell line with an aberrant karyotype of 64 chromosomes as characterized originally. Collectively, comparisons of our data with that of others highlights the necessity for (1) obtaining a reliable data set for genome-wide target analyses (preferably by retrieving all target sequences for each individual targeted clone) and (2) re-evaluating the genome-wide target profile of transposons (at least piggyBac and Tol2) in the specific stem cell type of therapeutic interest before advancing them to clinical uses.

The reliable data sets obtained in this study allow us to perform in-depth sequence analyses of their targets without ambiguity. The sequence logo of Tol2 detected subtle but significant information present within the first 11 base pairs on the 3' end of Tol2 target sites. Furthermore, as indicated in Table 3 despite the fact that the target sequence of the most frequently targeted Tol2 hotspot (4 out of 207) is actually located within LINEs and shares more than $97 \%$ sequence identity with two other sequences in the genome, Tol2 only targeted to this particular site but not to other similar sequences. Collectively, these observations strongly suggest even though no distinct features of Tol2 target sequences can be readily identified, Tol2, like piggyBac, also targets in a selective manner in the host genome. The in-depth sequence analyses also revealed the following important features of piggyBac targeting preference: (1) TTAA sites in a particular sequence context are targeted by piggyBac, as opposed to arbitrary TTAA sites, (2) there is no direct correlation between piggyBac hotspots (and Tol2 hotspots as well) and the activity of genes either contained within or near the hotspots, and (3) at least the first 100 nucleotides on either side of piggyBac target site seem to be important for piggyBac target selection, and a subtle change in the primary sequence within this $200 \mathrm{bp}$ interval may result in losing its potential for piggyBac targeting. These insights will provide a solid knowledge basis for engineering piggyBac transposase to achieve site-specific therapeutic gene targeting.

Powerful genetic tools enabling the probing of functions of both coding and non-coding genome sequences are urgently needed to facilitate the progress in determining the genetic factors that contribute to our uniqueness as human beings in a post-genomic era. The fact that piggyBac favorably targets intragenic chromosomal regions makes it a great tool for uncovering the functions of protein coding genes. Transposable elements are often considered "junk" DNA in the human genome. An increasing body of evidence, however, suggests that a fraction of these repetitive sequences are active and play import roles in epigenetic gene regulation $[43,44,46,47]$. The preference of Tol2 to target genomic repeats makes it an ideal tool for revealing new functions of transposable elements residing in our genome. Collectively, the non-overlapping genome-wide target profiles of piggyBac and Tol2 potentially makes them complementary research tools for studying the human genome.

Genotoxicity caused by a single integration event mediated by the retrovirus-based vector has resulted in the development of T-cell leukemia in 5 of 20 patients treated for SCID with one death reported [39]. Hence, no wild type DNA transposon is considered safe for gene therapy since they all introduce transgenes into a host genome in a random fashion. Indeed, our genomewide target profiling of piggyBac in HEK 293 revealed a piggyBac hotspot located within the coding region of gephyrin, a scaffold protein implicated in colon cancer and adult T-cell leukemia [40-42]. Most active mammalian genome manipulating enzymes, including viral integrases and DNA transposase, must therefore be molecularly modified to achieve the ultimate goal in gene therapy: targeting the therapeutic gene into a predetermined genomic site where the therapeutic gene can be stably and faithfully expressed without disturbing the global gene expression profile. Put into perspective, piggyBac is by far the most promising vector system for gene therapy, as piggyBac transposase is the only one capable of being molecularly modified without substantially losing activity (reference 15 and this study).

\section{Conclusions}

The transposon-based tool box for mammalian genomic manipulations is expanding. Here, we engaged in a sideby-side comparison of two highly effective mammalian active transposons, piggyBac and Tol2, to evaluate their pros and cons for gene discovery and gene therapy. We report the identification of the shortest piggyBac TRDs, micro- $\mathrm{PB}$, which have a higher transposition efficiency in HEK 293 than that of the previously reported piggyBac minimal terminal repeat domains, mini-piggyBac. Our genome-wide target profiling reveals that piggyBac and Tol2 display complementary targeting preferences, making them suitable tools for uncovering the functions of protein-coding genes and transposable elements, respectively, in the human genome. Our results suggest that piggyBac is the most promising DNA transposon 
for gene therapy because its transposase is likely the most amenable mammalian genetic modifier for being molecularly engineered to achieve site-specific therapeutic gene targeting. Our in-depth sequence analyses of piggyBac targets revealed that the sequence context near and within a considerable distance from the TTAA piggyBac target site is highly important in site selection. Based on this observation, it is clear that in order to advance piggyBac for a clinical use in gene therapy, a safe and favorable site for piggyBac targeting in the genome of the appropriate therapeutic stem cell should first be identified, followed by the engineering of piggyBac transposase to achieve site-specific gene targeting.

\section{Methods}

\section{Transposon constructs}

The plasmid construction described in this study followed the protocol of Molecular Cloning, $3^{\text {rd }}$ edition, CSHL [48]. The sequences of all constructs involving PCR-based cloning were confirmed by DNA sequencing. The process of each construction is described briefly as follows:

\section{(1) pPB-cassette3short}

The short piggyBac TRDs (i.e. 746 808 3' LTR and 1426 1460 5' LTR as in pXL-BacII $[29,30]$ ) were obtained from the PCR mixture consisting of the following four pairs of primers; pB-11-KpnI (atcgggtaccttaaccctagaaagataatcatattg), pB-5-forward (ggtaccCCCTAGAAAGATAATCATATTGTGACGTACGTTAA AGATAATCATGCGTAAAATTGACGCATGctcgag), pB-6-reverse (gagctcCCCTAGAAAGATAGTCTGCGTAAAATTGACGCATGccaccgcggtggatttaa atctcgagcatgcgtca), and pB-12-SacI (cgatgagctcttaacctagaagatagtctgcg). The resulted amplicon containing both 67 bp 5' and 40 bp 3' TRD with SwaI and Xho I restriction sites in between was cloned into pBS-SKII through Kpn I and Sac I restriction sites to obtain the pPBendAATT. The same cassette (containing the hygromycin resistant gene driven by SV40, the replication origin, ColE1, and the kanamycin resistant gene) as in pXLBacII-cassette [15] was inserted between short piggyBac TRDs in pPBendAATT through the blunt-ended Xho I site to make the intermediate construct, pPBcassette3. To generate the pPB-cassette3short, pPBcassette 3 was digested with Acc65 I and Afl III to remove the ampicillin resistant gene and the $\mathrm{f} 1$ replication origin. The remaining DNA fragment was blunt-ended followed by self-ligation to generate the final construct, pPBcassette3short.

\section{(2) pTol2mini-cassette}

To construct the Tol2 donor with short TRDs, two separated PCR products were generated by two sets of primers, Tolshort-1 (atcgggtaccatttaaatCAGAGGTGTAAAGTACTTG)/Tolshort-2 (tatcaagcttagatctagAAGTGATCTCCAAAAAATAAG) and Tolshort-3
(ctaagcttgatatcaacggatccAATACTCAAGTACAATTTTAATGG)/Tolshort-4 (cgatgagctcatttaaatCAGAGGTGTAAAAAGTACTC), respectively using the Tol2endcassette [15] as a template. Next, these two PCR products were served as templates to produce the third PCR product using the Tolshort-1 and Tolshort-4. The third PCR product was cloned into the Kpn I and Sac I site of pBS-SK II vector to generate the miniTol2-end. The same cassette as described in section (1) above was then inserted into the EcoR V site of miniTol2end to generate $\mathrm{pTol} 2 \mathrm{mini}$-cassette.

\section{(3) pPRIG-piggyBac}

To generate pPRIG-piggyBac, the coding sequence of the piggyBac transposase was PCR amplified from pcDNA3.1Aneo-piggyBac [15] using primer piggyBac-10 (ATCGGAATTCACCATGGGTAGTTCTTTAGACG) and primer piggyBac-11 (AAGGCACAGTCGAG GCTG). The PCR product was cloned into the EcoR I and Not I site of the pPRIG vector.

\section{(4) pPRIG-Tol2}

The coding sequence of the Tol2 transposase was obtained from the Xba I/BamHI restriction fragment of pcDNA3.1 $\Delta$ neo-Tol2 [15] and then inserted into the Stu I and BamHI sites of pPRIG vector.

\section{(5) $p C M V-M y c-p i g g y B a c$}

The same fragment containing the ORF of piggyBac transposase as described in section (3) above was cloned into the pCMV-myc vector (Clontech, Inc) to generate pCMV-Myc-piggyBac.

\section{(6) pPRIG-HA-Tol2}

A pair of complementary oligos containing the sequence of the HA tag was synthesized, annealed and inserted into the BamHI site of pPRIG-Tol2 vector to generate pPRIG-HA-Tol2 which expresses a N-terminal HA tagged Tol2 transposase. The clones with a correct orientation were obtained and verified by DNA sequencing.

\section{(7) $p P R I G-T o l 2-H A$}

pPRIG-Tol2-HA expressing the C-terminal HA tagged Tol2 transposase was constructed by swapping the restriction fragment of XcmI and SphI of pCR4-TOPOTol2HAc (the detailed procedure regarding the construction of this plasmid is upon requested) with those in pPRIG-Tol2.

\section{Cell culture and transposition assay}

HEK 293 cells were maintained in MEM $\alpha$ medium (HyClone) supplemented with 10\% FBS (HyClone), 100 units/ml penicillin, and $100 \mu \mathrm{g} / \mathrm{mL}$ streptomycin. The details for the transposition assays were described previously [32].

\section{Activity assay of the piggyBac transposase}

A similar procedure as detailed previously [32] was used to co-transfect $100 \mathrm{ng}$ of piggyBac donor, with various 
amount of the piggyBac helper, pCMV-Myc-piggyBac, ranging from $0-300 \mathrm{ng}$ into $1.2 \times 10^{5}$ of HEK 293 cells. pcNDA3.1 $\triangle \mathrm{NEO}$, an empty vector used in our previous study (Wu et.al 2006), was used to top the total amount of DNA transfected to $400 \mathrm{ng}$. Each transfection condition was done in triplicate. Twenty four hours after transfection, one fifth of transfected cells were subjected to transposition assay. The remaining transfected cells $(4 / 5)$ in triplicate were pooled and grew in a $35-\mathrm{mm}$ plate for another twenty four hours before being subjected to Western blotting. For Western blotting, total proteins were extracted using RIPA buffer (50 $\mathrm{mM}$ Tris, $\mathrm{pH} 8.0,150 \mathrm{mM} \mathrm{NaCl}, 1 \%$ Nonidet P-40, $0.1 \%$ SDS, $0.5 \%$ sodium deoxycholate, and 1:100 diluted proteinase inhibitor cocktail) and quantified using the Lowry assay (Biorad). Twenty $\mu \mathrm{g}$ of total proteins were separated by SDS-PAGE on a $8 \%$ acrylamide gel. After electrophoresis, the gel were transferred to PVDF membranes (millipore). The membrane was then probed with anti-Myc antibody at 1:1000 (Clontech) and anti- $\alpha$ actin antibody (Calbiochem) at 1:10,000. After three washes, a secondary antibody, peroxidase-conjugated goat anti mouse IgG, was added. After incubation and three washes, the secondary antibodies were subsequently detected by ECL.

\section{Retrieving chromosomal sequences flanking the transposon targets by plasmid rescue}

The same transfection procedure detailed previously was used to transfect the piggyBac donor, pXLBacII-cassette, and Tol2 donor, Tol2ends-cassette, along with their corresponding helper, pPRIG-piggyBac and pPRIG-Tol2, respectively, into HEK 293 cells using Fugene HD (Roche). The transposition efficiency for pXLBacII-cassette and Tol2ends-cassette is around $1 \sim 2 \%$. To avoid the duplication of the same targeted cell, twenty four hours after the addition of Fugene HD, transfected cells were subjected to a series dilutions and then grown in the hygromycin $(100 \mu \mathrm{g} / \mathrm{ml})$ containing culture medium at a density (about $20 \sim 30$ colonies per $100-\mathrm{mm}$ plate as estimated from $1 \sim 2 \%$ of transposition rate) enabling for isolating individual colonies without cross-contamination. Two weeks after selection, colonies which were at a great distance away from adjacent colonies were individually cloned and expanded until reaching confluence on 100-mm dishes. Genomic DNA of individual clones was isolated and subjected to plasmid rescue. Detailed procedures for plasmid rescue were described previously [32]. Plasmids rescued from the same targeted clone were digested with Hinf II (4-cutter restriction enzyme). For each targeted clone, only plasmids showing different Hinf II digestion patterns were subjected to sequencing. Based on the Hinf II digestion pattern, all of the colonies isolated displayed a distinct repertoire of rescued plasmids indicating that each isolated colony was indeed derived from different targeted cells.

\section{Q-PCR and Q-RT-PCR}

HEK 293 cDNA was obtained using the FastLane Cell cDNA kit (Qiagen). One point three $\mu \mathrm{l}$ of cDNA and $0.125 \mu \mathrm{g}$ (predetermined by a series dilution of genomic DNA) of HEK 293 genomic DNA were subjected to QPCR using primers listed in 2. Q-RT-PCR was performed using SYBR Green PCR Master Mix (Applied Biosystems) in $20 \mu \mathrm{l}$ of reaction on 7500 Fast Real-Time PCR System (Applied Biosystems). The expression level of individual transcripts was determined by dividing the copy number of each cDNA with the copy number of the corresponding gene using following formula: $2^{\text {(Ctge- }}$ nomic DNA-CtcDNA). The relative expression level between each gene and GAPDH was calculated by the ratio of the gene expression level between the two.

\section{Bioinformatic analyses}

Target sites were identified in build hg18 of the human genome using Blat [37], with a sequence identity cutoff of $95 \%$. Human genes were obtained from RefSeq [49], and 2,075 cancer-related genes were taken from the CancerGenes database [50]. Upon counting the number of genes within $n$ base intervals, all overlapping genes were first merged to avoid over-counting. CpG islands were taken from the UCSC Genome browser "CpG Island" track, which identifies $\mathrm{CpG}$ islands based on the methods of Gardiner-Garden and Frommer [51]. Repeat elements predictions were obtained from RepeatMasker [52]. Only insertions whose first 100 bases are contained within a repeat element were considered to overlap a repeat element. To estimate the significance of the tendency of insertions to be located proximal to CpG islands, we compared the number of insertions located within 2,000 bases of a CpG island to the number expected by chance. The expected number was calculated for each transposon type by picking $\mathrm{N}$ random regions in the genome of the same size (in bases) as the given transposon, where $\mathrm{N}$ is the total number of insertions for the given transposon. This procedure was repeated 1,000 times, and the mean and standard deviation of the number of random insertions points within 2,000 bases of a CpG island across the 1,000 random trials were used to obtain a Z-score (and associated P-value) for the actual number of insertions located within 2,000 bases of a CpG island.

\section{Additional material}

Additional file 1: Table S1. Clusters of piggyBac and To/2 target sites located within a $10 \mathrm{~kb}$ interval in HEK 293. A table lists piggyBac and 
Tol2 targets that are clustered within a $10 \mathrm{~Kb}$ interval to the adjacent targets

Additional file 2: Table S2. A list of primer pairs for Q-RT-PCR analyses. This file contains sequence information for primers used for QuantitativePCR and Quantitative RT-PC analyses

\section{Abbreviations}

LINE: Long interspersed nuclear element; SINE: Short Interspersed nuclear Element; TRD: Terminal repeat domain; TIR: terminal inverted repeat; PCR: polymerase chain reaction; Q-RT-PCR: Quantitative reverse transcription PCR

\section{Acknowledgements}

The PPRIG vector was kindly provided by Dr. Patrick Martin, Université de Nice, Parc Valrose, 06108 Nice, France. The piggyBac vector system was kindly provided by Dr. Max Scott, Institute of Molecular BioSciences, Massey University, Palmerston North, New Zealand. The Tol2 vector system was kindly provided by Dr. Loichi Kawakami, National Institute of Genetics, Shizuoka, Japan. We thank Dr. Scott C. Schuyler for critical reading of the manuscript and Miss Chih-Jou Chen for assisting the preparation of the manuscript. Dr. Sareina C.-Y. Wu was supported by the funding of Chang Gung Molecular Medicine Research Center (EMRPD190181) and in part by a grant from the Children's Medical Research Foundation and a NIH T32 training grant. Miss Pei-Cheng Chung was supported by the funding of Chang Gung Molecular Medicine Research Center (EMRPD190181). This study was supported by Taiwan National Science Council (NMRPD180021), Chang Gung Memorial Hospital (CMRPD180041), and in part by YongKang Veterans Hospital (VHYK9804) and GenomeFrontier, INC.

\section{Author details}

'Department of Biomedical Sciences, Chang Gung University, 259 Wen-Hwa 1st Road, Kwei-Shan, Tao-Yuan 333, Taiwan. ${ }^{2}$ Banting and Best Department of Medical Research and Donnelly Centre for Cellular and Biomolecular Research University of Toronto, 112 College Street, Toronto, Ontario, M5 S 3E1, Canada. ${ }^{3}$ YongKang Veterans Hospital, 427 Fuxing Road, Yongkang City, Tainan 71051, Taiwan. ${ }^{4}$ Molecular Medicine Research Center, Chang Gung University, 259 Wen-Hwa 1st Road, Kwei-Shan, Tao-Yuan 333, Taiwan. ${ }^{5}$ Institute of Molecular Medicine and Genetics and Institute of Neuroscience, Georgia Health Sciences University, 1120 15th Street, Augusta, Georgia 30912, USA.

\section{Authors' contributions}

YM, and SW participated in experimental design, analysis and drafted the manuscript. MW contributed to the computational analyses and aided in manuscript preparation. PC contributed to the Q-RT-PCR and Q-PCR analyses. HY contributed to processing chromosomal sequence information. RY contributed to the discussion and preparation of the manuscript. All authors read and approved the final manuscript.

\section{Competing interests}

Dr. Yaa-Jyuhn James Meir is partially supported by GenomeFrontier, INC.

Received: 29 September 2010 Accepted: 30 March 2011

Published: 30 March 2011

\section{References}

1. McClintock B: The origin and behavior of mutable loci in maize. Proc Natl Acad Sci USA 1950, 36:344-355.

2. Hayes F: Transposon-based strategies for microbial functional genomics and proteomics. Annu Rev Genet 2003, 37:3-29.

3. Spradling AC, Rubin GM: Transposition of cloned P elements into Drosophila germ line chromosomes. Science 1982, 218:341-347.

4. Bellen HJ, O'Kane CJ, Wilson C, Grossniklaus U, Pearson RK, Gehring WJ: Pelement-mediated enhancer detection: A versatile method to study development in Drosophila. Genes Dev 1989, 3:1288-1300.

5. Thibault ST, et al: A complementary transposon tool kit for Drosophila melanogaster using P and piggyBac. Nat Genet 2004, 36:283-287.

6. Plasterk RH: The Tc1/mariner transposon family. Curr Top Microbiol Immunol 1996, 204:125-143.
7. Osborne Bl, Baker B: Movers and shakers: Maize transposons as tools for analyzing other plant genomes. Curr Opin Cell Biol 1995, 7:406-413.

8. Ivics Z, Hackett PB, Plasterk RH, Izsvák Z: Molecular reconstruction of Sleeping Beauty, a Tc1-like transposon from fish, and its transposition in human cells. Cell 1997, 91:501-510.

9. Ivics Z, Meng MA, Mátés L, Boeke JD, Nagy A, Bradley A, Izsvák Z: Transposon-mediated genome manipulation in vertebrates. Nature Methods 2009, 6:415-422

10. Koga A, Suzuki M, Inagaki $H$, Bessho $Y$, Hori $H$ : Transposable element in fish. Nature 1996, 383:30

11. Kawakami K: Tol2: a versatile gene transfer vector in vertebrates. Genome Biol 2007, 8(Suppl 1):S7.

12. Ryan BJ, Wangensteen KJ, Balciunas D, Schmedt C, Ekker SC, Largaespada DA: Efficient Transposition of To/2 in the Mouse Germline. Genetics 2009, 183:1565-1573.

13. Fraser MJ, Brusca JS, Smith GE, Summers MD: Transposon-mediated mutagenesis of a baculovirus. Virology 1985, 145:356-361.

14. Ding $S$, Wu X, Li G, Han M, Zhuang Y, Xu T: Efficient transposition of the piggyBac (PB) transposon in mammalian cells and mice. Cell 2005, 122:473-483.

15. Wu SC, Meir JY, Coates CJ, Handler SM, Pelczar P, Kaminsk J: piggyBac is a flexible and highly active transposon as compared to Sleeping Beauty, Tol2 and Mos1 in mammalian cells. Proc Natl Acad Sci USA 2006, 103:15008-15013.

16. Wang W, Lin C, Lu D, Ning Z, Cox T, Melvin D, Wang X, Bradley A, Liu P: Chromosomal transposition of piggyBac in mouse embryonic stem cells. Proc Natl Acad Sci USA 2008, 105:9290-9295.

17. Liang Q, Kong J, Stalker J, Bradley A: Chromosomal mobilization and reintegration of Sleeping Beauty and piggyBac transposons. Genesis 2009, 47:404-408.

18. Woltjen $K$, Michael IP, Mohseni $P$, Desai R, Mileikovsky $M$, Hämäläinen $R$, Cowling R, Wang W, Liu P, Gertsenstein M, Kaji K, Sung HK, Nagy A: piggyBac transposition reprograms fibroblasts to induced pluripotent stem cells. Nature 2009, 458:766-770.

19. Yusa K, Rad R, Takeda J, Bradley A: Generation of transgene-free induced pluripotent mouse stem cells by the piggyBac transposon. Nat Methods 2009, 6:363-369.

20. Hacein-Bey-Abina S, Garrigue A, Wang GP, Soulier J, Lim A, Morillon E, et al: Insertional oncogenesis in 4 patients after retrovirus-mediated gene therapy of SCID-X1. J Clin Invest 2008, 118:3132-3142.

21. Deakin $C T$, Alexander $I E$, Kerridge $\mathrm{I}$ : Accepting risk in clinical research: is the gene therapy field becoming too risk-averse? Mol Ther 2009, 17:1842-1848.

22. Balciunas D, Wangensteen KJ, Wilber A, Bell J, Geurts A, Sivasubbu S, Wang X, Hackett PB, Largaespada DA, Mclvor RS, Ekker SC: Harnessing a high cargo-capacity transposon for genetic applications in vertebrates. PLoS Genet 2006, 2:e169.

23. VandenDriessche T, Ivics Z, Izsvák Z, Chuah MK: Emerging potential of transposons for gene therapy and generation of induced pluripotent stem cells. Blood 2009, 114:1461-1468.

24. Kang $Y$, Zhang $X$, Jiang W, Wu C, Chen C, Zheng Y, Gu J, Xu C: Tumordirected gene therapy in mice using a composite nonviral gene delivery system consisting of the piggyBac transposon and polyethylenimine. BMC Cancer 2009, 9:126.

25. Hackett PB, Largaespada DA, Cooper A: Transposon and transposase system for human application. Mol Ther 2010, 18:674-83.

26. Geurts AM, Yang Y, Clark KJ, Liu G, Cui Z, Dupuy AJ, et al: Gene transfer into genomes of human cells by the Sleeping Beauty transposon system. Mol Ther 2003, 8:108-117.

27. Kay MA: Site-directed transposon integration in human cells. Nucleic Acids Research 2007, 35:e50.

28. Mátés L, Chuah MK, Belay E, Jerchow B, Manoj N, Acosta-Sanchez A, et al: Molecular evolution of a novel hyperactive Sleeping Beauty transposase enables robust stable gene transfer in vertebrates. Nat Genet 2009, 41:753-61.

29. Li X, Harrel RA, Handler AM, Beam T, Hennesy K, Fraser MJ Jr: piggyBac Internal sequences are necessary for efficient transformation of target genomes. Insect Mol Biol 2005, 14:17-30.

30. Fraser MJ: Home of piggyBac [http://piggybac.bio.nd.edu/]

31. Urasaki A, Morvan G, Kawakami K: Functional dissection of the Tol2 transposable element identified the minimal cis-sequence and a highly 
repetitive sequence in the subterminal region essential for transposition. Genetics 2006, 174:639-49.

32. Wu SC, Maragathavally KJ, Coates CJ, Joseph M, Kaminski JM: Steps toward targeted insertional mutagenesis with class II transposable elements. Methods in Molecular Biology 2007, 435:139-151.

33. Wilson MH, Coates CJ, George AL: PiggyBac transposon-mediated gene transfer in human cells. Mol Ther 2007, 5:139-145.

34. Grabundzija I, Irgang M, Mátés L, Belay E, Matrai J, Gogol-Döring A, Kawakami K, Chen W, Ruiz P, Chuah MK, VandenDriessche T, Ivics Z: Comparative analysis of transposable element vector systems in human cells. Mol Ther 2010, 18:1200-9.

35. Galvan DL, Nakazawa Y, Kaja A, Kettlun C, Cooper LJ, Rooney CM, Wilson MH: Genome-wide mapping of piggyBac transposon integrations in primary Human T cells. J Immunother 2009, 32:837-44.

36. Huang X, Guo H, Tammana S, Jung YC, Mellgren E, Bassi P, Cao Q, Tu ZJ, Kim YC, Ekker SC, Wu X, Wang SM, Zhou X: Gene transfer efficiency and genome-wide integration profiling of Sleeping Beauty, Tol2, and piggybac transposons in human primary T Cells. Mol Ther 2010, 6:1-11.

37. Kent WJ, Sugnet CW, Furey TS, et al: The Human Genome Browser at UCSC. Genome Res 2002, 12:996-1006[http://genome.ucsc.edu/cgi-bin/ hgGateway]

38. Shaw G: The HEK293 Cell Database.[http://www.mbi.ufl.edu/ shaw/293. html].

39. Fischer A, Hacein-Bey-Abina S, Cavazzana-Calvo M: 20 years of gene therapy for SCID. Nature Immunology 2010, 11:457-460.

40. Reddy-Alla S, Schmitt B, Birkenfeld J, Eulenburg V, Dutertre S, Boöhringer C, Goötz M, Betz H, Papadopoulos T: PH-Domain-driven targeting of collybistin but not $\mathrm{Cdc} 42$ activation is required for synaptic gephyrin clustering. European Journal of Neuroscience 2010, 31:1173-1184.

41. Ruginis T, Taglia L, Matusiak D, Lee B-S, Benya RV: Consequence of GastrinReleasing Peptide Receptor Activation in a Human Colon Cancer Cell Line: A Proteomic Approach. Journal of Proteome Research 2006, 5:1460-1468.

42. Ozawa T, Itoyama T, Sadamori N, Yamada Y, Hata T, Tomonaga M, Isobe M: Rapid isolation of viral integration site reveals frequent integration of HTLV-1 into expressed loci. J Hum Genet 2004, 49:154-165.

43. Slotkin RK, Martienssen R: Transposable elements and the epigenetic regulation of the genome. Nat Rev Genet 2007, 8:272-85.

44. Sijen T, Plasterk RHA: Transposon silencing in the Caenorhabditis elegans germline by natural RNAi. Nature 2003, 426:310-314.

45. Shi X, Harrison RL, Hollister JR, Mohammed A, Fraser MJ Jr, Jarvis DL: Construction and characterization of new piggyBac vectors for constitutive or inducible expression of heterologous gene pairs and the identification of a previously unrecognized activator sequence in piggyBac. BMC Biotechnology 2007, 18:;:5.

46. Sanjida H, Haig HK Jr: Many LINE1 elements contribute to the transcriptome of human somatic cells. Genome Biology 2009, 10:R100.

47. Chow JC, Ciaudo C, Fazzari MJ, Mise N, Servant N, Glass JL, Attreed M, Avner P, Wutz A, Barillot E, Greally JM, Voinnet O, Edith Heard: LINE-1 activity in facultative heterochromatin formation during $\times$ chromosome inactivation. Cell 2010, 141:956-969,

48. Sambrook J: Molecular Cloning A Laboratory Manual , 3 .

49. Pruitt KD, Tatusova T, Klimke W, Maglott DR: NCBI Reference Sequences: current status, policy and new initiatives. Nucleic Acids Research 2009, 37 D32-D36.

50. Higgins ME, Claremont M, Major JE, Sander C, Lash AE: CancerGenes: a gene selection resource for cancer genome projects. Nucleic Acids Research 2007, 35:D721-D726.

51. Gardiner-Garden M, Frommer M: CpG islands in vertebrate genomes. $J$ Mol Biol 1987, 196:261-82.

52. Smit AFA, Hubley R, Green P: RepeatMasker Open-3.0 1996 [http://www. repeatmasker.org].

doi:10.1186/1472-6750-11-28

Cite this article as: Meir et al: Genome-wide target profiling of piggyBac and Tol2 in HEK 293: pros and cons for gene discovery and gene therapy. BMC Biotechnology 2011 11:28.

\section{Submit your next manuscript to BioMed Central and take full advantage of:}

- Convenient online submission

- Thorough peer review

- No space constraints or color figure charges

- Immediate publication on acceptance

- Inclusion in PubMed, CAS, Scopus and Google Scholar

- Research which is freely available for redistribution

Submit your manuscript at www.biomedcentral.com/submit
Biomed Central 